\title{
Material Scarcity and Unethical Economic Behavior: A Systematic Review and Meta-Analysis
}

Christian Elbaek ( $\square$ chel@mgmt.au.dk )

Aarhus University https://orcid.org/0000-0002-7039-4565

Panagiotis Mitkidis

Aarhus University https://orcid.org/0000-0002-9495-7369

Lene Aarøe

Aarhus University https://orcid.org/0000-0003-4551-3750

Tobias Otterbring

University of Agder https://orcid.org/0000-0002-0283-8777

Article

Keywords: resource scarcity, socioeconomic status, morality, unethical economic behavior, meta-analysis

Posted Date: October 11th, 2021

DOI: https://doi.org/10.21203/rs.3.rs-800481/v2

License: (c) (1) This work is licensed under a Creative Commons Attribution 4.0 International License.

Read Full License 
1 Material Scarcity and Unethical Economic Behavior: A Systematic Review

2 and Meta-Analysis

3 Christian T. Elbæk*

4 Aarhus University, Department of Management

5 Fuglesangs Allé 4, 8210 Aarhus V, Denmark

6 chel@mgmt.au.dk

7

$8 \quad$ Panagiotis Mitkidis

9 Aarhus University, Department of Management

10 Fuglesangs Allé 4, 8210 Aarhus V, Denmark

11 Duke University, Social Science Research Institute, Center for Advanced Hindsight

12334 Blackwell Street, Suite 320, Durham, NC 27701

13

14 Lene Aarøe

15 Aarhus University, Department of Political Science

16 Bartholins Allé 7, 8000 Aarhus C, Denmark

17

18 Tobias Otterbring

19 University of Agder, Department of Management

20 Universitetsveien 17, 4630 Kristiansand, Norway

21 Institute of Retail Economics

22 Kungsgatan 27, 11156 Stockholm, Sweden

23

$24 *$ Corresponding Author 


\section{$1 \quad$ Abstract}

2 Individuals around the globe experience different forms of material resource scarcity in terms

3 of aspects such as hunger, thirst, or financial strains. As experiences of material scarcity have

4 been found to make individuals more risk-taking, impulsive, and focused on regaining 5 resources in the short-term, a growing body of research has investigated how such scarcity 6 affects moral economic behavior. Yet, findings remain mixed and at times contradictory, thus 7 calling for a systematic meta-analytical review on this overarching topic. In this pre-registered 8 systematic review and meta-analysis, we evaluate qualitatively and quantitatively how material

9 resource scarcity affects moral economic behavior. We analyze a comprehensive dataset 10 including 44 published and unpublished studies comprising a total of 6,921 respondents across 11 four distinct types of material scarcity: financial scarcity, physiological scarcity, scarcity 12 reminders, and lower social class. Our findings show that acute scarcity significantly increases 13 the propensity to engage in unethical economic behavior $\left(g_{\text {financial }}=.24, g_{\text {physiological }}=.39\right.$, $14 g_{\text {reminders }}=.32$ ). Importantly, we find no evidence that chronic experiences of scarcity in the 15 form of low social class affect unethical economic behavior $\left(g_{\text {social class }}=.02\right)$. These results 16 appear robust to the influence of publication bias and contextual sensitivity. We discuss how 17 these findings advance our understanding of the psychological and moral consequences of scarcity and elaborate on implications for public policy.

20 Keywords: resource scarcity, socioeconomic status, morality, unethical economic behavior, 21 meta-analysis 
1 Unethical economic behaviors, such as fraud, theft, corruption, and embezzlement, cost

2 societies billions of dollars every year (Gee \& Button, 2019). Albeit big scandals, like the

3 Volkswagen Dieselgate emissions scandal, the Siemens corruption scandal, and Danske

4 Bank's involvement in money laundering for some of the world's worst criminals, are often

5 the examples that make it to the news headlines, the aggregated effects of small-scale unethical

6 economic behavior can have equally or even more detrimental consequences for the societies

7 and stakeholders. For instance, only in the U.S., misreporting liable income was estimated to

8 cost the tax authorities $\$ 458$ billion dollars in 2019 (United States Government Accountability

9 Office, 2019). Whether large or small in scale, unethical economic behavior has destructive

10 consequences for individuals, businesses, and societies in general, underscoring the importance

11 of understanding the human motivation to engage in such behavior as crucial for policy makers

12 (Ayal et al., 2015; Babakus et al., 2004; Gerlach et al., 2019; Mazar \& Ariely, 2006; Mitchell

13 et al., 2009; Transparency International, 2019).

14 Unethical economic behavior is here conceptualized as any sort of economic outcome

15 that occurs through immoral actions. Due to the endemic nature of unethical economic behavior

16 (Transparency International, 2019), studies within psychology, neuroscience, management,

17 marketing, and behavioral economics have investigated which factors might affect the

18 propensity to engage in such morally questionable behavior (Fischbacher \& Föllmi-Heusi,

19 2013; Gino et al., 2009; Greene \& Paxton, 2009; Kajackaite \& Gneezy, 2017; Kocher et al.,

20 2018; Mazar et al., 2008; Shalvi et al., 2015). Importantly, as the last two decades have seen a

21 rapid rise across disciplines in empirical work addressing the causes and consequences of

22 material resource scarcity (Dhurandhar, 2016; Griskevicius et al., 2013; Hamilton et al., 2019;

23 Huppert et al., 2020; Lee \& Zietsch, 2011; Nelson \& Morrison, 2005; Prediger et al., 2014;

24 Roux et al., 2015), an emerging body of research has started to investigate whether and how

25 experiences of material resource scarcity (such as hunger, thirst, or financial poverty) may 
1 influence people's propensity to engage in unethical economic behavior (DeWall et al., 2008;

2 Gino et al., 2011; Mead et al., 2009; Wang et al., 2017).

However, the evidence on the impact of material scarcity on unethical economic

4 behavior is characterized by seemingly mixed findings. Some studies suggest that material

5 scarcity increases unethical behavior (Birkelund \& Cherry, 2020; Goldsmith et al., 2018;

6 Prediger et al., 2014; Sharma et al., 2014; Yam et al., 2014) while other studies indicate that

7 material scarcity increases prosocial behavior (Bartos, 2016; DeWall et al., 2008; Häusser et

8 al., 2019; Herzenstein \& Posavac, 2019; Huppert et al., 2020). These mixed findings have also

9 spurred a new debate on how material scarcity affects decision-making more generally (Hall

10 et al., 2014; Mani et al., 2013; Mullainathan \& Shafir, 2014; Shah et al., 2012)

11 Here, we present the first pre-registered systematic review and meta-analysis on the

12 relationship between experiences of material scarcity and unethical economic behavior. Based

13 on the systematic review, we argue that it is important to distinguish between different types

14 of acute and chronic experiences of material scarcity to understand their impact on financial

15 outcomes. Specifically, we identify financial and physiological scarcity as well as reminders

16 of scarcity as three fundamental forms of acute scarcity, whereas social class constitutes a key

17 indicator of chronic scarcity.

18 Using this typology, we then provide the first meta-analysis on how material resource

19 scarcity might affect individuals' propensity to engage in unethical economic behavior.

20 Analyzing 44 published and unpublished studies including 6921 respondents, we find that

21 acute financial and physiological scarcity as well as reminders of scarcity significantly increase

22 individuals' propensity to engage in unethical economic behavior. Importantly, we find no

23 evidence that more chronic material scarcity, in the form of lower social class, impacts

24 unethical economic behavior. Thus, based on the extant body of published research, the

25 propensity to engage in dishonest behavior for direct monetary gains appears to operate 
1 irrespective of social class and is equally likely to occur among individuals from lower and

2 higher social classes.

Overall, the findings from the systematic review and the meta-analysis do not support

4 the general claim that scarcity increases the propensity to engage in unethical economic

5 behavior. Instead, our results highlight the importance of distinguishing between different

6 types of material scarcity, where only temporary or acute experiences of scarcity seem to

7 impact people's moral decision-making in the financial realm. Sensitivity analyses conducted

8 as part of our meta-analysis indicate that the results are not strongly impacted by contextual

9 sensitivity (cf. Van Bavel et al., 2016) and robust to the existence of publication bias (cf.

10 Mathur \& VanderWeele, 2020; Simonsohn et al., 2015).

11 Together, the results from the qualitative systematic review and the quantitative metaanalysis highlight that the seemingly mixed findings on the relationship between material

13 resource scarcity and unethical economic behavior can be disentangled by distinguishing

14 between different types of temporary and acute versus more chronic forms of scarcity.

15 Consequently, rather than focusing on consequences of "the scarcity mindset," scholars may

16 benefit from theorizing on the psychological architecture and consequences of different forms

17 of material scarcity. As acute experiences of material resource scarcity can in effect apply to

18 individuals around the globe, we argue that the current review has important implications for

19 the theoretical understanding of how material scarcity can distort human moral judgment and

20 decision-making and how policy initiatives aimed at hindering unethical behavior should 21 incorporate such considerations.

\section{Scarcity Effects on Decision-Making}

24 Research over the last decade has found robust evidence that scarcity in the form of hunger, 25 thirst, or financial strains induces myopic decision-making, where present, short-term gains are 
1 overvalued, while future possible gains are discounted (Loewenstein, 1996; Mani et al., 2013;

2 Mullainathan \& Shafir, 2014; Shah et al., 2012; Skrynka \& Vincent, 2019). Scholars have

3 suggested that scarcity taxes the mind, reducing "mental bandwidth" - an umbrella term used

4 to cover the cognitive functions associated with executive control and fluid intelligence -

5 leading scarcity-constricted individuals to "tunnel" attention (Mani et al., 2020; Mani et al.,

6 2013; Mullainathan \& Shafir, 2014; Shah et al., 2012). While this tunneling of cognitive

7 resources might increase the likelihood of obtaining material resources to balance the scarcity

8 (i.e., what is known as "the focus dividend"), it usually comes with a cost. Importantly, because

9 scarcity-constricted individuals tunnel attention towards the options that might best satisfy their

10 current needs, other resources and obligations are repeatedly neglected, leading to sub-optimal

11 prospective decision-making outcomes (Mani et al., 2013; Mullainathan \& Shafir, 2014; Piech

et al., 2010; Shah et al., 2012). Consistent with this notion, scholars have shown that individuals

who have matured in environments characterized by resource scarcity (i.e., low childhood

socioeconomic status) perform worse in tasks requiring cognitive inhibition, but are better able to shift attention, because such behavior is considered particularly useful in unpredictable environments (Mittal et al., 2015). Furthermore, research has provided evidence that scarcity significantly increases risk-taking and impulsive behavior in individuals (Griskevicius et al., 2013; Hamilton et al., 2019; Payne et al., 2017; Simpson et al., 2012), again pointing to potentially problematic decision-making due to scarcity.

Importantly, some research on how material scarcity affects decision-making argues that the "scarcity-mindset" is induced independent of the resource in question. That is, whether the current scarcity is experienced as a lack of food, water, or financial resources, the effect of this lack of necessary resources will lead to similar cognitive and behavioral outcomes across different types of material resource scarcity (Mullainathan \& Shafir, 2014). It should be noted that this conceptualization of scarcity does not entail that poor individuals are worse decision- 
1 makers (Mullainathan \& Shafir, 2014). Instead, it prescribes to the idea that cognizant

2 experiences of relative scarcity make the individual focus on regaining the lack of resources in

3 the short-term, regardless of the individual's social class or demographic profile.

5 Material Scarcity and Unethical Economic Behavior: A Systematic Review

6 The findings that material scarcity increases risk-taking, impulsiveness, and future discounting

7 have led scholars to hypothesize that scarcity increases unethical economic behavior based on

8 the argument that individuals constricted of resources exhibit an increased focus on regaining

9 the experienced lack of resources in the short term (Birkelund \& Cherry, 2020; Gino \& Pierce,

10 2010; Sharma et al., 2014; Yam et al., 2014). In what follows, we present a systematic review

11 of extant scientific studies on this topic, which aligned with the inclusion criteria for the

12 subsequent meta-analysis. The aim of this section is threefold: (1) to provide an in-depth overview of the different types of material scarcity that have been studied, (2) to delineate the types of manipulations and research designs that have been used in this overarching topic domain, and (3) to critically summarize the mixed nature of the existing findings. The contribution of this qualitative review is hence to provide a comprehensive theoretical overview of the current literature in this specific domain of moral psychology, in order to structure and increase the interpretability of the subsequent quantitative meta-analysis.

\section{Physiological Scarcity}

21 Some studies focus on food deprivation, indexed by self-reported hunger or physiological

22 levels of blood glucose, to test how this specific form of scarcity affects unethical economic behavior. Across five laboratory experiments, Yam et al. (2014) found that individuals experiencing physiological deprivation, either in the form of hunger or thirst, were more prone to engage in unethical behaviors that could alleviate these aversive experiences, but that such 
1 scarcity made individuals less prone to exhibit unethical behavior in unrelated consumption

2 domains. Williams et al. (2016) demonstrated a similar relationship by showing that individuals

3 restricted of food or water were more likely to engage in unethical behavior to increase their

4 chances of winning a prize, but only if the prize could alleviate their current lack of resources.

5 Hence, scarcity did not create a generalized spillover effect in unethical behavior across

6 domains, as has been shown to exist when it comes to prosocial behavior (Briers et al., 2006).

7 On the developmental level, results have indicated that scarcity in the form of hunger might

8 affect moral behavior. Koenig et al. (2004) found that experiences of resource scarcity, indexed

9 by maltreatment, significantly affected moral development in 5-year-old children. Specifically,

10 these authors' experimental results revealed that maltreated children engaged in significantly

11 more cheating and stealing behaviors compared to non-maltreated children, indicating that

12 resource scarcity can have detrimental consequences for the development of moral behavior

13 early on in an individual's life.

15 Financial Scarcity

16 While research on scarcity points towards a unified framework of effects, where any form of

17 material scarcity (be it thirst, hunger, or a lack of financial resources) exerts similar decisionmaking effects across domains (Mullainathan \& Shafir, 2014; Shah et al., 2012), a majority of research on material scarcity and unethical behavior has examined specifically how a relative

20 lack of financial resources affects decision-making. A possible reason for this could be that 21 relative scarcity in economic resources has received wide-spread attention beyond academia, in politics and the media, due to the alarming and increasing levels of economic inequality across the world (Alvaredo et al., 2018; Piketty, 2020).

Gino and Pierce (2010), investigated how economic inequality, as manipulated by resource allocation (allocated randomly or subjectively), affected moral behavior in the form 
1 of either helping or hurting others. Results showed that inequality significantly predicted

2 increased levels of dishonest behavior for individuals with less resources and a follow-up

3 experiment indicated that people behaved unethically to restore the perceived inequality. Also,

4 Sharma et al. (2014) showed that manipulating resource scarcity in the form of financial

5 deprivation lead individuals to cheat more for economic gains, and to judge such behavior as

6 being less immoral. This effect was mediated by whether individuals considered the

7 experienced deprivation as an acceptable reason for engaging in unethical behavior and if they

8 were made aware of that the unethical behavior could not alleviate the experienced scarcity, in

9 which case the effect no longer emerged (Sharma et al., 2014).

10 More recently, Birkelund and Cherry (2020) found that individuals experiencing

11 financial inequality (vs. equality) cheated significantly more for monetary resources in an experimental dishonesty task and justified such behavior as result of the experienced scarcity.

13 Relatedly, Gino and Pierce (2009b) investigated the influence of relative resource scarcity,

14 indexed by inequity in endowments between individuals, on unethical economic behavior in a

15 laboratory setting. Albeit the incentives for dishonest behavior varied, results consistently

16 showed that inequity between partners in the experiment increased cheating and, importantly,

17 that pure self-interest was not the prime mechanism in the causal chain; rather, individuals

18 engaged in cheating due to emotional reactions (i.e., envy) elicited by the perceived resource

19 scarcity. Results also indicated that dishonest behavior triggered by inequity made individuals

20 more inclined to engage in dishonest helping due to empathy with the less fortunate partner

21 (Gino \& Pierce, 2009b). The tendency to justify unethical behavior under scarcity as a part of

22 helping other resource deprived individuals was also supported in the work by Dubois et al.

23 (2015), who showed that individuals with lower social class were more likely to engage in

24 unethical behavior, only if such behavior could benefit their in-group. These findings suggest

25 two important psychological mechanisms regarding scarcity; (1) that reminders of one's 
1 relative lack of economic resources (compared to others) can increase the individuals' tendency

2 to engage in unethical economic behavior, and (2) that such behavior finds justification on the

3 basis of in-group altruism.

\section{$5 \quad$ Reminders of Scarcity}

6 Several studies have also examined how reminders and primes of scarcity might affect

7 cognition and behaviors related to morality. Within this research tradition, scholars have 8 demonstrated that individuals who exhibit a maximizing mindset (vs. a neutral mindset)

9 regarding resource acquisition engage in significantly more immoral behaviors, and that the

10 adoption of a maximizing mindset occurs due to cognitions related to scarcity (Goldsmith et

11 al., 2018). Seuntjens et al. (2019) showed that greedy individuals (with greed conceptualized as a form of competitive orientation) were more likely to engage in and justify unethical behavior, while simultaneously being more prone to accept bribes due to the temptation of monetary gains being higher for such individuals. Moreover, activating cognitions related to scarcity through conceptually congruent reminders has been shown to increase competitive orientation in individuals, leading to more selfish behavior by guarding monetary resources instead of donating to charity, unless such charity is self-beneficial (Roux et al., 2015).

Notably, Roux et al. (2015) provided evidence for the thesis that exposure to scarcity cues can both increase selfish or prosocial behavior but only if such behavior is self-beneficial and advances personal welfare. However, results from experimental work on moral behavior

21 have repeatedly shown that selfish behavior is a robust predictor of unethical behavior (Dubois et al., 2015; Engelmann \& Fehr, 2016; Gino \& Galinsky, 2012; Mead et al., 2009). Using reminders of scarcity in the form of visual exposure to inequality, Gino and Pierce (2009a)

24 demonstrated that the presence (vs. absence) of visual proximity to money increased economic cheating among individuals with smaller (vs. larger) monetary endowments. Specifically, by 
creating an environment where one's current relative financial scarcity was visually emphasized, the authors documented that participants cheated more to alleviate this state, with the cheating also provoking emotions of envy towards wealthy others. In a similar vein, an experiment by John et al. (2014) used performance-based pay-rates, and found that dishonesty emerged in individuals with lower pay-rates, but only when it was salient to them that there was an opportunity of gaining a higher pay-rate (relative to their own rate), again emphasizing the effects that relative scarcity has on activating a competitive orientation and a maximizing mindset (Goldsmith et al., 2018; Roux et al., 2015).

In relation to specific cognitions and behaviors stemming from scarcity, scholars have argued that such cognitive and behavioral responses could be the result of an evolutionary response to harsh environments. Notably, the use of fast life history strategies (i.e., short-term mating, low group altruism, higher criminal record, and higher risk taking) have been shown to emerge more frequently when resources are scarce (Griskevicius, Delton, et al., 2011; Griskevicius, Tybur, et al., 2011). Reynolds and McCrea (2015) employed a series of laboratory experiments to test if faster (vs. slower) life history strategies, as well as primes of faster (vs. slower) life history contingencies, would lead to exploitative and deceptive resource acquisition strategies. Their findings indicated that individuals with a fast life history strategy cheated more than individuals with a slow life history strategy, and that priming individuals with fast life history contingencies further increased cheating. There results provide evidence that experiences of resource scarcity, as indexed by life history strategies, increase unethical economic behavior, and that being reminded of one's lack of resources, by fast life history primes, can further increase the propensity to engage in unethical economic behavior to acquire resources. 


\section{$1 \quad$ Field Evidence}

2 While laboratory experiments represent a major source of scientific knowledge in the social 3 sciences, providing rigor and control (Falk \& Heckman, 2009), lab-based results might not 4 always be generalizable to naturally occurring environments or the real-world (Levitt \& List, 5 2007; Otterbring et al., 2020; Potters \& Stoop, 2016; Roe \& Just, 2009; Shadish et al., 2002).

6 Consequently, a series of studies have utilized lab-in-the-field experiments and field 7 experiments to study the effects of resource scarcity on unethical behavior among targeted 8 relevant populations in naturalistic settings (Gneezy \& Imas, 2017). Attending to this form of 9 work, Gatiso et al. (2015) conducted a dynamic lab-in-the-field experiment in a communally 10 managed forest in Ethiopia, finding that individuals exposed to resource scarcity engaged in 11 significantly more unethical behavior by overharvesting forest, thus leaving less available resources to other individuals. Furthermore, men were particularly prone to develop a competitive orientation during such circumstances, in line with previous research (Hamilton et al., 2019; Roux et al., 2015), which made them overharvest resources even more. The results additionally indicated that resource scarcity decreased cooperation between individuals for the common good (Gatiso et al., 2015). Prediger et al. (2014) employed a lab-in-the-field experiment in Namibia, providing evidence that individuals subjected to exposure of biomass resource scarcity were twice as 19 likely to engage in unethical behavior in the form reducing other individuals' income. Contrary to such findings, though, recent results from a lab-in-the-field experiment in Thailand have

21 provided evidence that unethical behavior might not increase through scarcity (Boonmanunt et al., 2020). Based on the argument that unethical behavior, such as corruption or tax evasion, is widespread in developing countries, Boonmanunt et al. (2020) investigated whether low-

24 income rice farmers in Thailand would be more inclined to cheat for monetary gains when experiencing resource scarcity. Unethical behavior was not found to increase by experiences 
1 of scarcity; however, reminders of social-norms of morality cut cheating behaviors for richer

2 individuals, while it had no effect for individuals experiencing resource scarcity (Boonmanunt 3 et al., 2020).

Aksoy and Palma (2019) investigated the effects of scarcity on cheating and in-group

5 favoritism, using a lab-in-the-field experiment in Guatemala. While the authors found no effect

6 of scarcity on cheating for economic gains in a well-validated cheating task (Fischbacher \&

7 Föllmi-Heusi, 2013), they did find that affluency (vs. scarcity) increased cheating behaviors

8 directed towards one's in-group. The mixed evidence of these findings taps into the ongoing

9 academic debate on how psychological constructs developed primarily in WEIRD (Western,

10 Educated, Industrialized, Rich and Democratic) contexts might not generalize to non-WEIRD

11 contexts (Henrich et al., 2010; Mitkidis et al., 2017; Muthukrishna et al., 2020; Xygalatas et 12 al., 2013).

Andreoni et al. (2017) used a natural field experiment in the Netherlands (i.e., a WEIRD culture) to test whether resource scarcity, as indexed by household income, could predict moral economic behavior. Specifically, the authors tested to what degree poor versus rich households would return "misdelivered" envelopes containing varying amounts of cash or a bank transfer card. Their findings showed that the rich (vs poor) acted significantly more prosocial by returning the misdelivered envelopes more often. While the specific study was framed around differences in prosocial economic behavior, these results show that individuals from poorer households to a lesser degree returned misdelivered envelopes with a monetary value for which they were not entitled, indicating that such individuals acted significantly more unethical than their wealthier counterparts (Andreoni et al., 2017).

However, other researchers have reached different conclusions, even in the same cultural context. Using objective measures of social class from a large Dutch population in a survey and an experiment, Trautmann et al. (2013) investigated differences in unethical 
1 behavior between individuals experiencing varying levels of resource scarcity. They found that

2 wealthier individuals (i.e., a trait of high social class) viewed cheating on taxes more 3 acceptable, while individuals with low employment status (i.e., a trait of low social class)

4 viewed such cheating as less acceptable. On the contrary, lying and accepting bribes was 5 considered less of an ethical violation by individuals' with lower social class (Trautmann et 6 al., 2013). Results like these highlight the current inconsistencies in the literature.

\section{Opposing Evidence}

9 While a relatively large part of the above cited evidence suggests a causal link between a lack 10 of financial resources and an increased inclination to engage in unethical behavior, other 11 studies have failed to provide evidence for this relationship and sometimes argued that the association might not be as linear as expected. For instance, in a series of six laboratory experiments, Dubois et al. (2015) showed that relative resource scarcity, indexed by social 14 class, negatively predicted unethical behavior, such that lower class individuals were more likely to participate in acts of unethical behavior, but only when such behavior was carried out to benefit others. However, if the unethical behavior was instead aimed at benefitting the individuals themselves, social class positively predicted the likelihood of engaging in unethical behavior (Dubois et al., 2015).

Grundmann and Lambsdorff (2017) found no effect of relative resource scarcity on unethical behavior in a task where participants could earn different levels of income based on

21 skill and luck, and then rolled a die (either privately or in public) that would determine their tax-rate of the earned income. Resource scarcity was manipulated by how much money individuals earned in the task, while participants had the opportunity to cheat in the experiment

24 by reporting a lower tax rate (i.e., a lower die roll) in the private die-roll. In contrast to the thesis that resource scarcity increases unethical behavior, Grundmann and Lambsdorff (2017) 
1 found that individuals with higher incomes cheated marginally more to gain a lower tax rate.

2 Similarly, Piff et al. (2012) showed that individuals with higher social class (both observed and

3 manipulated) were more likely to cheat to win a prize, steal goods from other people, and

4 engage in other non-economic acts of immorality, such as breaking the law while driving. Yet,

5 recent direct replications of this study have provided mixed results, as some scholars have been

6 able to successfully replicate the original findings (Clerke et al., 2018), while others have failed

7 to do so (Balakrishnan et al., 2017; Nowlin et al., 2018).

Aoki et al. (2010) investigated if deceptive behavior would be dependent on

9 socioeconomic status. Although they found a series of situational factors influencing the 10 propensity to engage in deceptive lying resembling previous findings in the area (for a review, see Gerlach et al., 2019), no effect of socioeconomic status on lying was found. Likewise, a recent study by Liu et al. (2019) showed that experiences of scarcity, in the form of low childhood socioeconomic status, was positively associated with dispositional greed, a wellknown antecedent of unethical behavior (Hilbig \& Zettler, 2015). Findings like these contribute to the mixed evidence of how scarcity can affect moral behavior by showing that scarcity, indexed by social class, can both increase and decrease unethical behavior.

Taken together, most prior research points to the possibility that experiences of material scarcity could increase individuals' tendencies to engage in unethical economic behavior. Nevertheless, a notable chunk of the reviewed literature has produced conflicting evidence, where this relationship either cannot be robustly established, is not sufficiently controlled for, 21 or where the direction of the effect follows the opposite pattern (i.e., affluency increases unethical economic behavior or scarcity decreases unethical behavior). Consequently, a metaanalysis on the topic is desirable to statistically establish and quantify the accumulated evidence that material resource scarcity exerts on unethical economic behavior. 


\section{Method}

\section{Search}

3 In August 2020, we performed a search across the academic databases Web of Science,

4 ScienceDirect, Scopus, and Google Scholar for all scientific works that investigated a 5 relationship between material resource scarcity and unethical economic behavior. A detailed

6 overview of the search terms, keywords, and subject areas used in the search process can be

7 found in our pre-registered review protocol (http://bit.ly/3t1zd8z). Additionally, we sent out 8 calls for unpublished literature on the subject to the mailing lists of the following research communities: Society for Personality and Social Psychology (SPSP), Society for Judgment and Decision Making (JDM), Society for Advancement of Behavioral Economics (SABE), The European Marketing Academy (EMAC), Association for Consumer Research (ACR), Academy of Marketing Science (AMS), American Marketing Association (AMA), Human Behavior and Evolution Society (HBES) and European Human Behavior and Evolution Association (EHBEA). Our database search and the calls for unpublished research covered all types of academic work on the subject (i.e., journal articles, working papers, pre-prints, book chapters, academic theses, etc.) to minimize the possibility of solely obtaining published research, which often tends to favor statistically significant results (Atkinson et al., 1982; Sterling, 1959; Sterling et al., 1995). In the remainder of this paper, we refer to each included piece of academic work as an article. Figure 1 depicts the search and selection process following the PRISMA statements (Moher et al., 2009; Moher et al., 2015; Page, McKenzie, et al., 2020; Page, Moher, et al., 2020). A detailed overview of all included articles can be found in Appendix A.

Notably, while the inclusion criteria of our pre-registered review protocol concerned research on how material resource scarcity might affect unethical economic behavior, our literature search, resulted in a series of articles which either investigated how scarcity might affect both unethical and prosocial behavior or which purely sought to investigate how scarcity 
1 might affect prosocial behavior. In theory, such articles should have been excluded, since

2 prosocial behavior cannot be considered a direct opposite of unethical behavior (Curry et al.,

3 2019; Graham et al., 2013; Tomasello \& Vaish, 2013). Nevertheless, we decided to include

4 such studies in a separate meta-analysis, reported in Appendix B, to further strengthen our

5 theoretical contribution of how resource scarcity might affect moral behavior in general, and

6 to aid future research on this overarching topic.

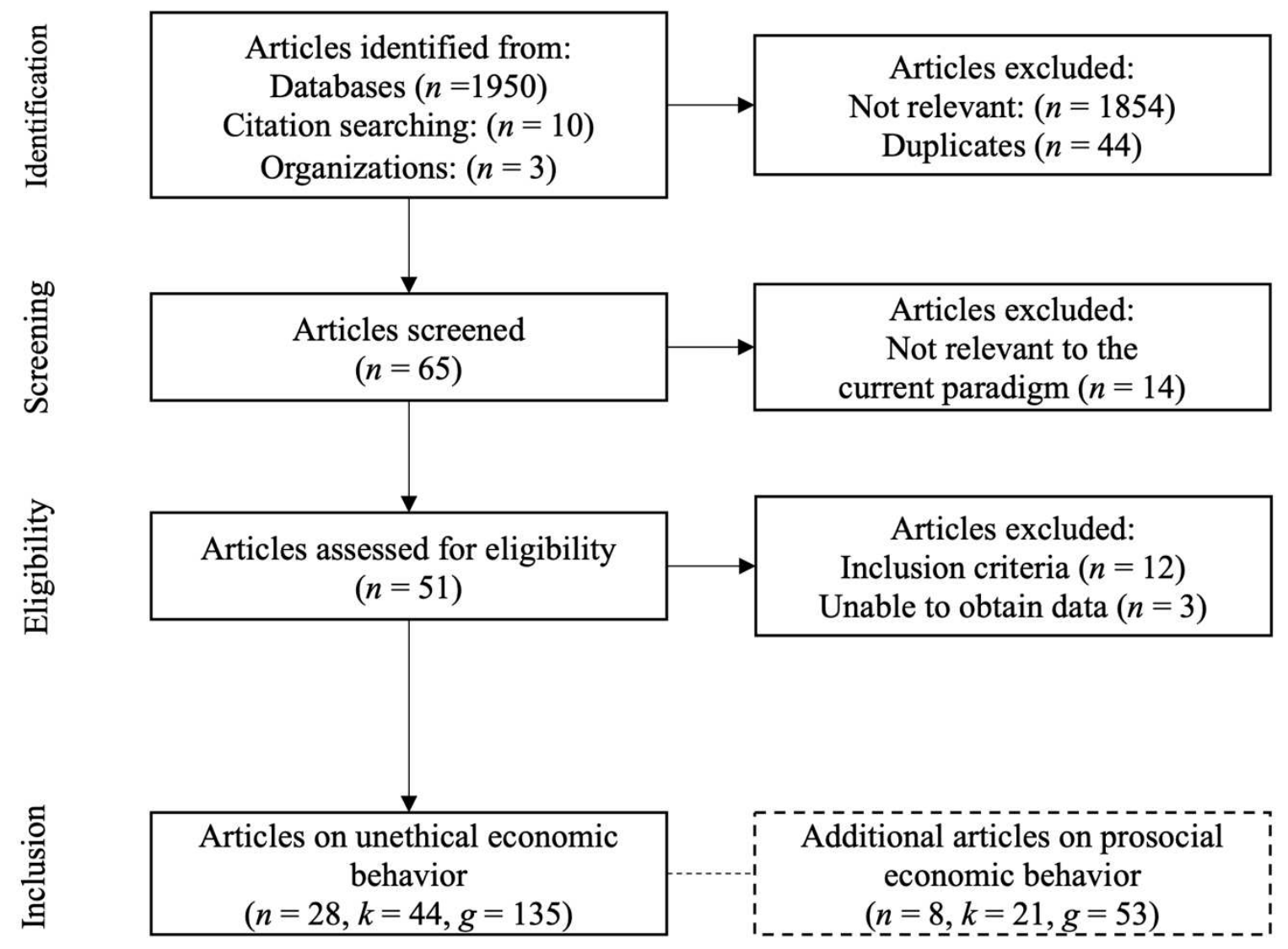

Figure 1. Process chart depicting the article search and inclusion process following the PRISMA standards (preferred reporting items for systematic reviews and meta-analyses). All articles were retrieved by the end of August 2020, with $n=$ number of articles, $k=$ number of independent studies, and $g=$ number of relevant effects sizes. Dotted lines represent articles included for the supplementary meta-analysis on the relationship between resource scarcity and prosocial economic behavior (see Appendix B). 


\section{Coding procedure}

3 The studies identified as eligible for inclusion were coded with respect to the dependent and

4 the independent variable. The coding procedure was carried out by two trained student coders,

5 with backgrounds in economics and cognitive science, and all coded information was verified

6 subsequently in correspondence with the first author. Specifically, we extracted information on

7 the dependent variable, independent variable(s), mediators, moderators, population type (e.g.,

8 students, children, etc.), location, site of the study (i.e., onsite vs. online), research design (e.g.,

9 lab experiment, lab-in-the-field experiment, etc.), and participant compensation from all the

10 included articles. Independent variables were divided into four sub-groups: Financial scarcity

11 (i.e., poverty and economic inequality), Social class (socioeconomic status), Physiological scarcity (i.e., hunger and thirst), and Reminders of scarcity (i.e., the activation of cognitions related to scarcity).

The coders also extracted the appropriate information from the reported test statistics in the articles to compute the effect size (Hedges' $g$ ) and standard error of all reported statistical tests, from randomly assigned experimental groups in the studies (See section, Effect Size Computation). All effect sizes and standard errors were checked and verified by both coders and the first author. In articles where the reported information was not sufficient to calculate the specific effect statistic $(N=18)$, we contacted the corresponding authors to obtain the relevant data needed for these calculations. All included articles as well as articles where it was not possible to obtain this information are listed in Appendix A.

Lastly, to examine whether variability in contextual sensitivity might moderate the generalizability and validity of our findings, we had three expert coders ( $\mathrm{PhD}$ candidates) evaluate all included articles for differences in contextual sensitivity (See section, Contextual Sensitivity Assessment) following the recommendations from Van Bavel et al. (2016). Here, 
1 contextual sensitivity indicates the degree to which the findings of any given article included

2 in this meta-analysis is perceived to be particularly sensitive to contextual differences in site,

3 location, time, and population. Following the ratings from the expert coders, the contextual

4 sensitivity means of the included articles were computed and coded into the dataset. Our

5 inclusion criteria resulted in a final dataset consisting of 28 articles (with a total of $N=6921$

6 observations) covering 44 studies.

7

\section{$8 \quad$ Effect Size Computation}

9 In order to pool the effects of the results in the included independent studies, we followed the 10 approach suggested by Borenstein et al. (2011) by standardizing the mean difference of all 11 results to the Hedges' $g$ effect size statistic. Here $g$ expresses the difference in means of two 12 randomly assigned experimental groups $\left(M_{1}\right.$ and $\left.M_{2}\right)$ in units of the pooled and weighted 13 standard deviation $\left(S D_{\text {pooled }}^{*}\right)($ Hedges, 1981):

$$
\begin{gathered}
g=\frac{M_{1}-M_{2}}{S D_{\text {pooled }}^{*}} \\
S D_{\text {pooled }}^{*}=\sqrt{\frac{\left(n_{1}-1\right) s_{1}^{2}+\left(n_{2}-1\right) s_{2}^{2}}{\left(n_{1}+n_{2}-2\right)}}
\end{gathered}
$$

16 While Hedges' $g$ is similar to the more commonly used Cohen's $d$ in the way that both assume

17 equal population variances and thus can be interpreted in the same way (Grissom \& Kim, 2005;

18 Hedges, 1981; Rosenthal et al., 1994), Hedges' $g$ accounts for unequal sample sizes by

19 weighting the pooled standard deviation. Furthermore, Cohen's $d$ has been shown to

20 overestimate the size of the actual effect in studies using smaller sample sizes $(n<50)$, which

21 Hedges' $g$ can be bias-corrected for (Hedges, 1981). Thus, overall, $g$ provides a more robust

22 and conservative estimate of the effect size than Cohen's $d$ (Hedges \& Olkin, 2014) and is 
1 considered the preferred effect size statistic for use in meta-analyses (Harrer et al., 2019;

2 Hedges \& Olkin, 2014).

All effect sizes were computed and coded individually in the dataset using the $R$ -

4 package esc for meta-analytic effect size computation (Lüdecke, 2018). Wherever possible,

5 effect sizes were calculated based on means, standard deviations, $F$-statistics, $t$-statistics, $r$ -

6 statistics, and $p$-values. All reported tests of a given article concerning the relationship between

7 resource scarcity and moral behavior were coded in the dataset and the main independent test

8 of each study was dummy coded ( 1 = main independent study result on unethical behavior, 2

9 = additional test of unethical behavior) to clarify the main findings of each article, while still

10 preserving individual tests of the relationship based on different sub-group analyses (e.g.,

11 gender differences, physiological differences, etc.). Studies reporting significant as well as

12 insignificant statistical tests were included in the dataset.

\section{Contextual Sensitivity Assessment}

15 Following the approach by Van Bavel et al. (2016), we recruited three expert coders (PhD 16 candidates) to evaluate the included articles for contextual sensitivity. Due to the 17 interdisciplinary nature of the included works, the three coders were recruited from three 18 distinct disciplines instead of only one, like in the original article. The three coders had graduate 19 training in Social Psychology, Economics, and Marketing. All coders were rewarded for their 20 work and their professional credentials are publicly available at OSF (http://bit.ly/3t1zd8z).

21 To ensure consistency in the coding, and following previous procedures, all coders were asked to practice their rating scheme on four studies, which were not included in the dataset,

23 prior to coding the included articles for contextual sensitivity (Van Bavel et al., 2016).

24 Subsequently, after verifying that the coders rated the studies in a similar and consistent 25 fashion, they rated the 28 articles included in the main meta-analysis. Expectedly, due to the 
1 large number of studies $(N=100)$ to be evaluated in the original article by Van Bavel et al.

2 (2016), the authors randomly picked 25 articles to be rated by all three coders, while 25 articles

3 were randomly assigned between the three coders. As our sample of articles was smaller $(N=$

4 28), all three coders evaluated each of the included articles, but in a randomized order. Vitally,

5 this process still allowed us to calculate interrater reliability between the coders through

6 intraclass correlation coefficients (Bartko, 1966; Fleiss \& Cohen, 1973).

In the rating of the articles, which was based on the title and the abstract, the three

coders assessed, how likely the findings of the individual articles were to vary by context,

9 which could be in terms of location (i.e., WEIRD vs. non-WEIRD countries/regions, cf.

10 Heinrich et al., 2010), sample type (i.e., student vs. non-student populations, differences in

11 racial characteristics, etc.), time (i.e., before vs. after large political changes, before vs. after recessions, etc.). Thus, the coding scheme aimed to capture a selection of macrolevel contextual effects that could be expected to influence the generalizability of the included research on scarcity and unethical economic behavior (Van Bavel et al., 2016). Importantly, the three coders were specifically instructed to only asses the contextual sensitivity of the included findings, while disregarding possible concerns on the quality of the research or the reputation of specific researchers or laboratories. The coders were only asked to evaluate the possibility that a given result might vary if the research was replicated directly in a different context than that of the original article. In practice, the coders read the title and abstract of a given article and replied to a Likert-type scaled item reading; "To what extent do you think 21 context (culture, time, place, etc. in which study is conducted) could affect the results of the study?", with scale points at 1 ("context is not at all likely to affect results"), 3 ("context is somewhat likely to affect the results") and 5 ("context is very likely to affect results") $(M=$ $242.95, S D=.63$ ) (Van Bavel et al., 2016). All articles were reviewed before-hand to verify that 
1 the titles and abstracts contained information on the contextuality, closely following the

2 procedure of the original work using the method (Van Bavel et al., 2016).

When the three coders had finished their individual assessment of the 28 articles, we

4 calculated interrater reliability, which revealed sufficient reliability $(\mathrm{ICC}=.479)$. Notably,

5 while we closely followed the approach of Van Bavel et al. (2016), our measure of interrater

6 reliability was considerably lower. We believe that this inconsistency exists because: (1) we

7 used a much smaller sample of studies $(N=28$ vs. $N=100)$, which led to a more sensitive

8 measure of interrater reliability (Mehta et al., 2018), and (2) our expert coders had training in

9 three distinct disciplines within the social sciences, which should allow for a much more robust

10 perspective of contextual sensitivity for studies stemming from more than one discipline,

11 contrary to that of the original article by Van Bavel et al. (2016). Furthermore, recent work on

12 interrater reliability in academic assessment on aspects such as grant proposals have found

13 much lower agreement among expert reviewer assessments, highlighting the complicated

14 nature of comparing scores across reviewers (Pier et al., 2018). Thus, we deemed our coders'

15 contextual sensitivity assessments to be sufficiently reliable and, consequently, calculated the

16 mean value of contextual sensitivity for each article, which was subsequently used as a measure

17 in our analyses.

\section{Analysis}

20 Firstly, following our pre-registered analysis outline (http://bit.ly/3t1zd8z) we employed a

21 random-effects model meta-analysis to pool the effect sizes of the included independent studies. This model was chosen a priori based on the assumption of exchangeability; that is,

23 we assumed the individual results not only to deviate from the true intervention effect due to

24 sampling error, but further assumed that additional variation would be present due to the studies

25 stemming from a series of different populations rather than a single population (Harrer et al., 
1 2019; Schwarzer et al., 2015). Hence, the formula for our random-effects model meta-analysis

2 is as follows:

$$
\widehat{\theta_{k}}=\theta_{F}+\epsilon_{k}+\zeta_{k}
$$

where $\widehat{\theta_{k}}$ denotes the observed effect size of an individual study $k, \theta_{F}$ denotes the true effect size, $\epsilon_{k}$ denotes the sampling error estimate, and $\zeta_{k}$ denotes the second source of error which is assumed to be present due to the effect size $\theta_{k}$ being a part of the distribution of true effect sizes (Borenstein et al., 2011; Harrer et al., 2019).

To estimate the variance of the distribution of true effects sizes, denoted $\tau^{2}$, we used the Hartung-Knapp-Sidik-Jonkman (HKSJ) method, as this estimation algorithm has been shown to provide more robust estimates of the variance of the pooled effect than the widely used DerSimonian-Laird method (IntHout et al., 2014). Utilizing this estimator provides more conservative results of $\tau^{2}$ and decreases the possibility of obtaining false positives due to small sample sizes or heterogeneity (Hartung, 1999; Hartung \& Knapp, 2001a, 2001b; Makambi, 2004). Furthermore, to estimate the amount of heterogeneity in the effect sizes, we computed $I^{2}$, estimating the percentage of variability in the included effect sizes, which can be determined not to be caused by sampling error (Higgins \& Thompson, 2002). As a robustness check, to address scholarly concerns on residual variance when using the HKSJ method (Jackson et al., 2017; Wiksten et al., 2016), we also conducted a sensitivity analysis comparing the HKSJ method to the DerSimonian-Laird method (See Appendix C). This analysis confirmed that the HKSJ method provided a more robust and conservative estimate of the overall effect size in the form of narrower confidence intervals. All analyses were performed using the dmetar package in $R$ (Harrer et al., 2019).

Still sticking to our pre-registered analysis outline, we then employed a novel approach to analyze publication bias in the included articles by the use of sensitivity analysis, as suggested by Mathur and VanderWeele (2020). This method is inherently different from the 
1 more classic methods, such as assessing funnel plot asymmetry using Egger's test (Egger et

2 al., 1997) and then using the Trim-and-Fill procedure (Duval \& Tweedie, 2000) to adjust the

3 meta-analysis, in which it is assumed that publication bias does not operate on very large

4 studies and where said bias is determined based on the size of the point estimates rather than

5 the $p$-values (Mathur \& VanderWeele, 2020). The use of this sensitivity analysis instead allows

6 for a relaxation of various statistical assumptions concerning the distributions and population

7 effects and simply requires the specification of a weighting function for which studies are more

8 (vs. less) likely to be published, making such an analysis much more robust to individual study

9 influences than more classic approaches (Mathur \& VanderWeele, 2020). In our case of a

10 random-effects model meta-analysis, publication bias was calculated using a numerical grid

11 search, tested with varying levels of this weighting function. The biggest advantage of this

12 method is that it allows for very intuitive classifications of the level of publication bias, as the

13 sensitivity analysis provides a direct quantification of the publication likelihood of affirmative

14 studies if such studies were to attenuate the population effects of the meta-analysis to null

15 (Mathur \& VanderWeele, 2020). All sensitivity analyses on publication bias in the meta-

16 analytic results were performed using the PublicationBias package in $R$ (Mathur \&

17 VanderWeele, 2020).

18 Finally, we performed our pre-registered analysis of contextual sensitivity, in which we

19 computed Pearson's correlation coefficients $(r)$ and Bayes Factor (BF) between our marker of

20 contextual sensitivity and the effect sizes, $p$-values, and sample sizes from the included articles

21 to examine the relationship between contextual sensitivity and these metrics. All correlation analyses were performed using the correlation package in $R$ (Makowski et al., 2020). 
1 Inspired by previous meta-analytic work (Orquin \& Kurzban, 2016), our analysis followed a

2 hierarchical breakdown strategy, in which we initially analyzed a global model of all included

3 studies before breaking them down to the subgroup level, as defined by the independent

4 variables. The results are presented in Table 1. The key variables of interest in this analysis is

5 the Standardized Mean Difference (SMD) in the form of Hedges' $g$, the percentage of

6 variability in effect sizes $I^{2}$, and the between study variance in the form of $\tau^{2}$.

The analysis of all included studies revealed a significant overall effect size of 0.2237 ,

corresponding to a medium effect of resource scarcity on unethical economic behavior by

9 current standards (Funder \& Ozer, 2019). The results of the global model, however, also

10 revealed substantial heterogeneity $I^{2}=82 \%$, comparable to what has been observed in recent

11 meta-analytic work on unethical behavior (Gerlach et al., 2019).

Grouping the analysis by the subgroup defined by the main independent variable

13 strongly reduced the degree of heterogeneity for studies on social class, $I^{2}=47.2 \%$ and studies

14 on physiological scarcity, $I^{2}=23.3 \%$, although the subgroup of articles on financial scarcity

15 accounted for a large degree of the observed heterogeneity in the overall model, $I^{2}=89.2 \%$.

16 The second-level subgroup analysis revealed a marginally significant effect size estimate of

170.2606 for the studies on financial scarcity, statistically significant effect sizes of 0.3207 and

180.3893 for studies on reminders of scarcity and physiological scarcity, respectively, and an

19 insignificant effect size estimate of 0.0185 for studies on social class. 
Table 1

Main Results of the Effect of Resource Scarcity on Unethical Behavior

Results prior to heterogeneity adjustment

\begin{tabular}{lccccccc}
\multicolumn{1}{c}{ Group } & $k$ & $N$ & SMD & $95 \%$ CI & $p$ & $I^{2}$ & $\tau^{2}$ \\
\hline All studies & 44 & 6921 & 0.2237 & {$[0.0793 ; 0.3680]$} & 0.0032 & $82.0 \%$ & 0.1931 \\
Financial Scarcity & 21 & 3136 & 0.2606 & {$[-0.0227 ; 0.5440]$} & 0.0694 & $89.2 \%$ & 0.3508 \\
Reminders of Scarcity & 3 & 575 & 0.3207 & {$[0.1435 ; 0.4980]$} & 0.0161 & $0.0 \%$ & 0.0006 \\
Physiological Scarcity & 9 & 686 & 0.3893 & {$[0.1710 ; 0.6076]$} & 0.0034 & $23.3 \%$ & 0.0494 \\
Social Class & 11 & 2524 & 0.0185 & {$[-0.1422 ; 0.1792]$} & 0.8030 & $47.2 \%$ & 0.0419
\end{tabular}

Results post heterogeneity adjustment

\begin{tabular}{lccccccc}
\multicolumn{1}{c}{ Group } & $k$ & $N$ & SMD & $95 \%$ CI & $p$ & $I^{2}$ & $\tau^{2}$ \\
\hline All studies & 38 & 6037 & 0.2073 & {$[0.0981 ; 0.3165]$} & 0.0005 & $65.5 \%$ & 0.0850 \\
Financial Scarcity & 15 & 2252 & 0.2376 & {$[0.0219 ; 0.4532]$} & 0.0331 & $73.5 \%$ & 0.1237 \\
Reminders of Scarcity & 3 & 575 & 0.3207 & {$[0.1435 ; 0.4980]$} & 0.0161 & $0.0 \%$ & 0.0006 \\
Physiological Scarcity & 9 & 686 & 0.3893 & {$[0.1710 ; 0.6076]$} & 0.0034 & $23.3 \%$ & 0.0494 \\
Social Class & 11 & 2524 & 0.0185 & {$[-0.1422 ; 0.1792]$} & 0.8030 & $47.2 \%$ & 0.0419 \\
\hline
\end{tabular}

Note. $k=$ number of studies, $N=$ sample size, $\mathrm{SMD}=$ Standardized Mean Difference by Hedges' $g, 95 \% \mathrm{CI}=95 \%$ confidence interval, $p=p$-value, $I^{2}=$ percentage of variability in effect sizes, $\tau^{2}=$ between-study variance.

To explore the observed heterogeneity, we conducted a GOSH (Graphical-Display-of-

4 Heterogeneity) analysis (Olkin et al., 2012), a more sophisticated method to asses individual

5 study influence in meta-analysis than the commonly used Leave-One-Out analysis

6 (Viechtbauer \& Cheung, 2010). In this analysis, we fitted our global model and subgroup

7 model to all possible subsets, $2^{k-1}$, of the data, by the use of a supervised machine learning

8 algorithm, known as three clustering, to detect any specific heterogeneity clusters (i.e. extreme

9 outliers) in our data (Harrer et al., 2019). The analysis revealed that four articles $(k=6$;

10 Andreoni et al., 2017; Gatiso et al., 2015; Gino \& Pierce, 2009a; Gino \& Pierce, 2010)

11 accounted for $16.5 \%$ of the observed heterogeneity in the global model as well as $15.7 \%$ of the

12 observed heterogeneity in the subgroup of financial scarcity. Thus, to obtain a more precise 
1 estimate of the true effect, we subsequently ran the analysis without these extreme outliers.

2 Rerunning the analysis without these studies reduced the heterogeneity of the global model to $3 \quad I^{2}=65.5 \%$ and yielded a revised, smaller and statistically significant pooled effect size 4 estimate of 0.2073 . Furthermore, the heterogeneity of the three subgroups (social class, 5 reminders of scarcity, and physiological scarcity) remained unchanged, while the heterogeneity 6 of the subgroup of studies on financial scarcity was reduced to $I^{2}=73.5 \%$, resulting in a 7 statistically significant pooled effect size of 0.2376 for this subgroup. A forest plot based on 8 the heterogeneity adjusted subgroup analysis is presented in Figure 2. 
Author(s)

Subgroup $=$ Financial scarcity

Aksoy et al., 2019 (1)

Andreoni et al., 2017 (1)

Aoki et al., 2010 (1)

Birkelund et al., 2020 (1.1)

Boonmanunt et al., 2020 (1)

Boonmanunt et al., 2020 (2)

Gatiso et al., 2015) (1)

Gino et al., 2009 (1)

Gino et al., 2009 (2.1)

Gino et al., 2009 (3.1)

Gino \& Pierce, 2010 (1.1)

John et al., 2013 (1.1)

John et al., 2013 (2.1)

Mitkidis et al., 2018a (1)

Mitkidis et al., 2018b (1)

Mitkidis et al., 2018b (2)

Neville, 2012

Prediger et al., 2014 (1.1)

Sharma et al., 2013 (1.1)

Sharma et al., 2013 (2.1)

Sharma et al., 2013 (3.1)

Subgroup Effect

Heterogeneity: $I^{2}=74 \%, \tau^{2}=0.1237, p<0.0001$

Subgroup $=$ Social Class

Balakrishna et al., 2017 (1.2) (R)

Balakrishna et al., 2017 (2.2) (R)

Balakrishna et al., 2017 (3.2) (R)

Balakrishna et al., 2017 (4.2) (R)

Clerke et al., 2018 (1.1) (R)

Clerke et al., 2018 (2.1) (R)

Nowlin et al., 2018 (1) (R)

Piff et al., 2012 (3)

Piff et al., 2012 (6.2)

Daubman et al., 2013 (R)

Trautmainn et al., 2013

Subgroup Effect

Heterogeneity: $I^{2}=47 \%, \tau^{2}=0.0419, p=0.0412$

Subgroup $=$ Reminders of Scarcity

Goldsmith et al., 2017 (2.1)

Goldsmith et al., 2017 (3)

Reynolds et al., 2015 (1.1)

Subgroup Effect

Heterogeneity: $I^{2}=0 \%, \tau^{2}=0.0006, p=0.8072$

Subgroup = Physiological Scarcity

Koenig et al., 2004 (3)

Koenig et al., 2004 (9)

Williams et al., 2016 (2.1)

Williams et al., 2016 (3.1)

Yam et al., 2015 (1.1)

Yam et al., 2015 (2.1)

Yam et al., 2015 (3.1)

Yam et al., 2015 (4.1)

Yam et al., 2015 (5.1)

Subgroup Effect

Heterogeneity: $I^{2}=23 \%, \tau^{2}=0.0494, p=0.2361$

Overall Effect

Prediction interval

Heterogeneity: $I^{2}=65 \%, \tau^{2}=0.0850, p<0.0001$
Standardised Mean

Difference

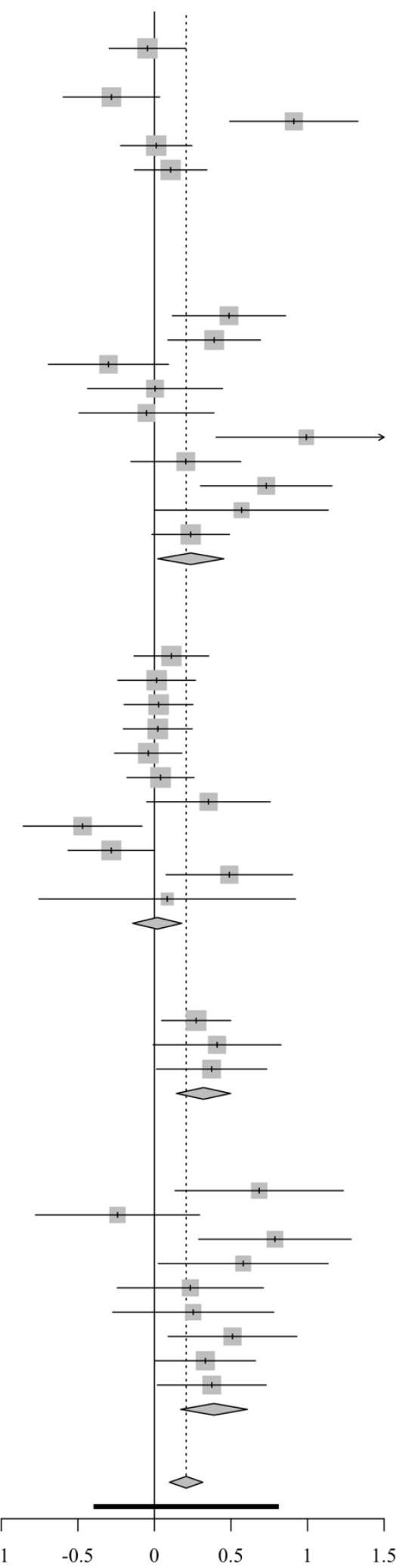

g

95\% CI Weigth

$-0.05[-0.30 ; 0.20] \quad 3.2 \%$

$-0.46[-0.67 ;-0.25] \quad 0.0 \%$

$-0.28[-0.60 ; 0.03] \quad 2.9 \%$

$0.91 \quad[0.49 ; 1.33] \quad 2.5 \%$

$0.01[-0.22 ; 0.24] \quad 3.2 \%$

$0.11[-0.13 ; 0.34] \quad 3.2 \%$

$-0.81[-1.18 ;-0.43] \quad 0.0 \%$

$1.36[0.76 ; 1.96] \quad 0.0 \%$

$1.11 \quad[0.68 ; 1.53] \quad 0.0 \%$

$1.42[0.90 ; 1.93] \quad 0.0 \%$

$-0.62[-0.99 ;-0.25] \quad 0.0 \%$

$0.49[0.12 ; 0.86] \quad 2.7 \%$

$0.39[0.09 ; 0.69] \quad 3.0 \%$

$-0.30[-0.69 ; 0.09] \quad 2.6 \%$

$0.00[-0.44 ; 0.44] \quad 2.4 \%$

$-0.05[-0.49 ; 0.39] \quad 2.4 \%$

$0.99[0.40 ; 1.58] \quad 1.8 \%$

$0.20[-0.15 ; 0.56] \quad 2.7 \%$

$0.73[0.30 ; 1.16] \quad 2.4 \%$

$0.57[0.00 ; 1.14] \quad 1.9 \%$

$0.24[-0.02 ; 0.49] \quad 3.2 \%$

$0.24[0.02 ; 0.45] \quad 39.9 \%$

$0.11[-0.13 ; 0.35] \quad 3.2 \%$

$0.01[-0.24 ; 0.27] \quad 3.2 \%$

$0.03[-0.20 ; 0.25] \quad 3.3 \%$

$0.02[-0.20 ; 0.25] \quad 3.3 \%$

$-0.04[-0.26 ; 0.18] \quad 3.3 \%$

$0.04[-0.18 ; 0.26] \quad 3.3 \%$

$0.35[-0.05 ; 0.76] \quad 2.5 \%$

$-0.47[-0.86 ;-0.08] \quad 2.6 \%$

$-0.28[-0.56 ; 0.00] \quad 3.0 \%$

$0.49[0.08 ; 0.90] \quad 2.5 \%$

$0.08[-0.75 ; 0.92] \quad 1.2 \%$

$0.02[-0.14 ; 0.18] \quad 31.3 \%$

$0.27[0.05 ; 0.50] \quad 3.3 \%$

$0.41[-0.01 ; 0.83] \quad 2.5 \%$

$0.37[0.01 ; 0.73] \quad 2.7 \%$

$0.32[0.14 ; 0.50] \quad 8.4 \%$

$0.68 \quad[0.13 ; 1.23] \quad 2.0 \%$

$-0.24[-0.78 ; 0.29] \quad 2.0 \%$

$0.79[0.29 ; 1.28] \quad 2.1 \%$

$0.58[0.03 ; 1.13] \quad 1.9 \%$

$0.23[-0.24 ; 0.71] \quad 2.2 \%$

$0.25[-0.27 ; 0.78] \quad 2.0 \%$

$0.51[0.09 ; 0.93] \quad 2.5 \%$

$0.33[0.01 ; 0.66] \quad 2.8 \%$

$0.37[0.02 ; 0.73] \quad 2.7 \%$

0.39 [ $0.17 ; 0.61] \quad 20.4 \%$

$0.21[0.10 ; 0.32] 100.0 \%$ [-0.39; 0.81$]$ 
Figure 2. Forest plot, adjusted for heterogeneity, of the effect sizes for each of the four subgroups as well as the overall effect. Error bars represent $95 \%$ confidence intervals. Grey diamonds depict the pooled effect for the subgroups. The grey diamond connected to the dotted line depicts the overall effect of the model. The black line depicts the prediction interval of the overall model. Articles marked with (R) denotes replication attempts of Piff et al. (2012).

Overall, the second-level model adjusted for heterogeneity supports an analysis of the included data at the subgroup level. Specifically, our model shows that resource scarcity in the

3 form of (1) financial scarcity, (2) reminders of scarcity, and (3) physiological scarcity

4 significantly affects individuals' propensity to engage in unethical economic behavior. Social 5 class, however, does not affect individuals' tendency to engage in unethical behavior. On the 6 global level, our model results in a medium effect size (.21) on the relationship between 7 material resource scarcity and unethical economic behavior.

As a robustness check, and to further asses the relationship between resource scarcity and unethical behavior, we fitted a model with every extracted effect size from all included studies (See Appendix C). While this resulted in a model in which one study was represented by several effect sizes, and thus a redundancy in sample sizes, the model confirmed our main model's pooled estimate of a medium-effect sizes estimate (.20) across 135 effects and 26,901 individuals.

15 Sensitivity to Publication Bias

16 To assess the validity and robustness of the derived effects in the meta-analysis, it is essential

17 to evaluate the sensitivity of the result to publication bias. A widespread way to do this is to evaluate funnel plot asymmetry by the use of Egger's test (Egger et al., 1997) and if funnel 
1 asymmetry exists, to correct the meta-analytic results by the use of the Trim-and-Fill procedure

2 (Duval \& Tweedie, 2000). However, these methods rely on the assumption that publication

3 bias does not exist in studies with large point estimates because publication bias is evaluated

4 based on the point estimate instead of the level of statistical significance (Mathur \&

5 VanderWeele, 2020). This means that such methods provide an inaccurate estimation of

6 publication bias if the included articles contain studies with small effect sizes, because these

7 effect sizes would distort the symmetry of the funnel plot (Debray et al., 2018; Zwetsloot et

8 al., 2017).

To circumvent the limitations linked to the above methods, we conducted a sensitivity analysis of publication bias, as recommended by Mathur and VanderWeele (2020). This sensitivity analysis estimates the amount of publication bias that is required to shift the metaanalytic estimate to zero. In our case, the sensitivity analysis estimates the $n$-fold times, referred to as the $S$-value, that studies with significant point estimates (affirmative studies) would need to be published compared to studies with insignificant point estimates (non-affirmative studies) in order to shift the model point estimate to null (Mathur \& VanderWeele, 2020). A significance funnel plot of the analysis is depicted in Figure 3. Our analysis showed that for publication bias to shift the result of our meta-analytic estimate to null, affirmative studies (in our case $N=18$ ) would need to be close to 7 -fold $(\mathrm{S}=6.98)$ more likely to be published than non-affirmative studies (in our case $N=26$ ), hence indicating that considerable amounts of publication bias would be required to distort our findings. These findings indicate that the results of the meta-analysis are fairly robust to the influence of publication bias, at least by means of conventional tests to detect this bias source (Mathur \& VanderWeele, 2020). 


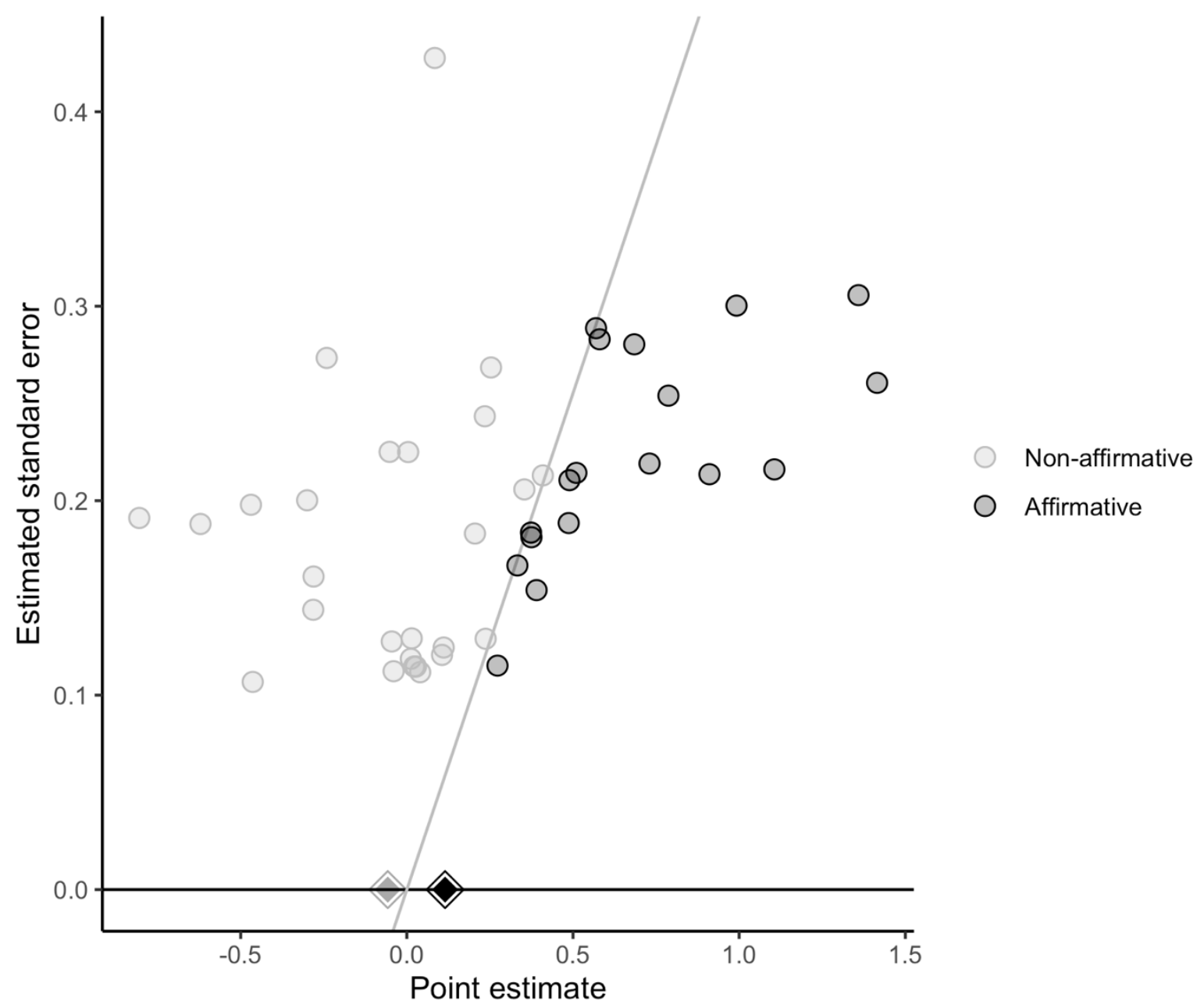

Figure 3. Significance funnel plot of the meta-analysis, based on the sensitivity analysis of publication bias in the included studies. Diagonal line indicates $p=.05$. Grey dots indicate non-affirmative studies. Black dots indicate affirmative studies. Black diamond indicates meta-analytic estimate of the random-effects model (0.22). Grey diamond indicates worstcase meta-analytic estimate (-0.0607).

As a further robustness check of publication bias, we carried out a P-curve analysis to detect to what degree the included literature would be sensitive to data mining (i.e., $p$-hacking)

4 (Simonsohn et al., 2014a, 2014b; Simonsohn et al., 2015). The P-curve for statistically $5 \quad$ significant studies $(\alpha=.05)$ is depicted in Figure 4. 


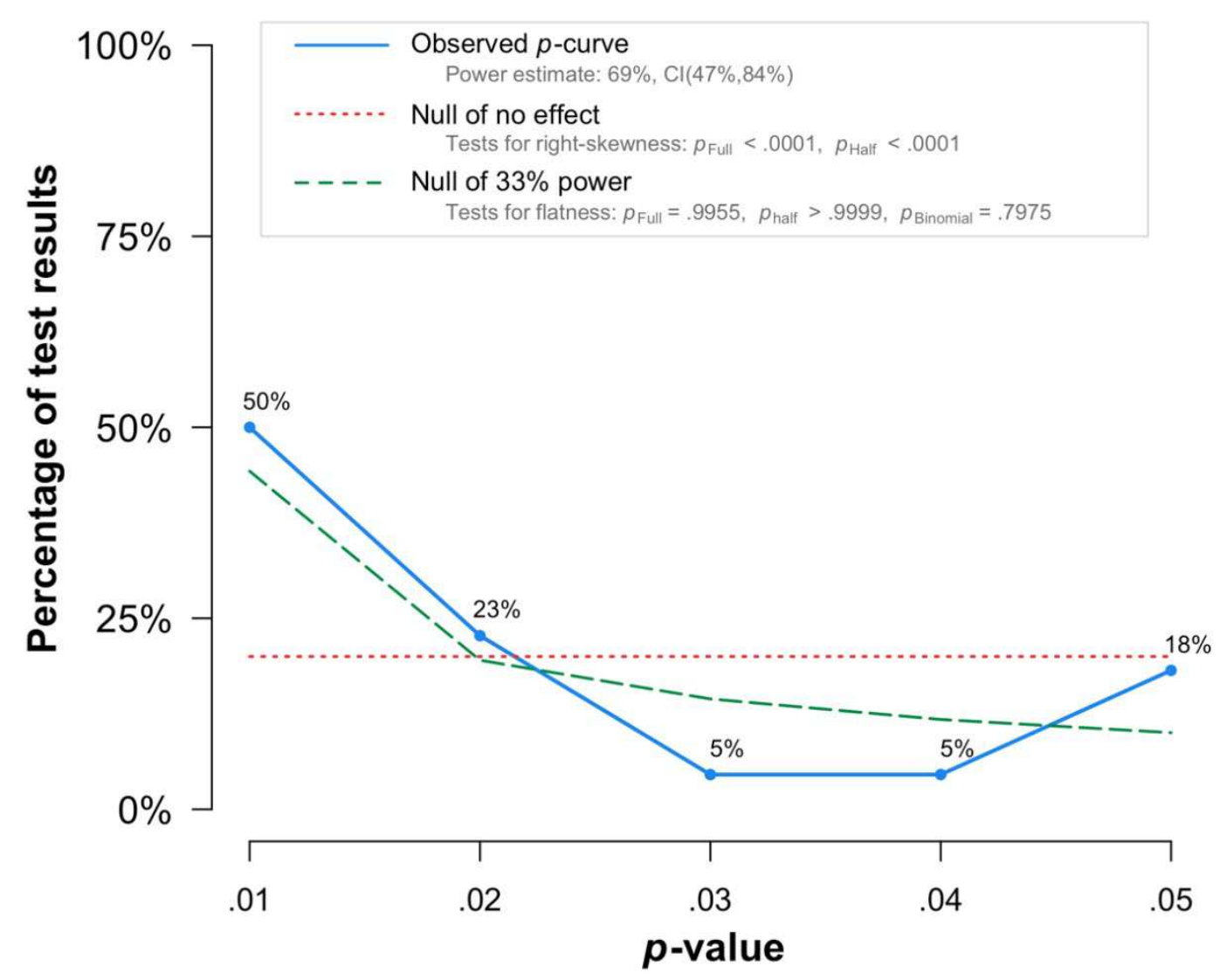

Figure 4. $P$-curve of all included studies with significant $p$-values $(p<.05) . P$-curve analysis shows no visible signs of data mining (i.e. $p$-hacking) in the included literature, as measured by a test of skewedness.

The results of the P-curve analysis revealed that the curve was significantly right2 skewed $(\mathrm{z}=-6.049, p<0.001)$, while the test of curve flatness was insignificant $(\mathrm{z}=2.612, p$ 3 > 0.999 ). The mean post-hoc statistical power for the significant studies was $69 \%$, with a $95 \%$ 4 confidence interval ranging from $47.3 \%$ to $84.2 \%$. These results suggest that a "true" effect is 5 present in the included studies, meaning that the findings cannot easily be explained through 6 publication bias or $p$-hacking (Harrer et al., 2019; Simonsohn et al., 2014b). Thus, the results 7 from the sensitivity analysis and the P-curve analysis indicate that, even under the assumption 
1 of some level of publication bias, our meta-analysis still provides a fairly robust estimate of

2 the pooled effect of resource scarcity on unethical economic behavior.

\section{Contextual Sensitivity}

5 The results of our analysis of contextual sensitivity of the included studies disproved the

6 prediction that individual study characteristics would be correlated with the rated level of 7 contextual sensitivity in a (Bayesian) Pearson's correlation. Results are reported in Table 2.

Table 2

Main Results of the Contextual Sensitivity Analysis

\begin{tabular}{ccccc}
\hline & $\begin{array}{c}\text { Effect Sizes } \\
r(\mathrm{BF})[95 \% \mathrm{CI}]\end{array}$ & $\begin{array}{c}\text { Standard Errors } \\
r(\mathrm{BF})[95 \% \mathrm{CI}]\end{array}$ & $\begin{array}{c}\text { P-Values } \\
r(\mathrm{BF})[95 \% \mathrm{CI}]\end{array}$ & $\begin{array}{c}\text { Sample Sizes } \\
r(\mathrm{BF})[95 \% \mathrm{CI}]\end{array}$ \\
\hline Contextual Sensitivity & $\begin{array}{c}0.09(0.389) \\
{[-0.22,0.37]}\end{array}$ & $\begin{array}{l}-0.19(0.671) \\
{[-0.46,0.11]}\end{array}$ & $\begin{array}{c}0.06(0.361) \\
{[-0.24,0.35]}\end{array}$ & $\begin{array}{c}0.07(0.365) \\
{[-0.24,0.36]}\end{array}$
\end{tabular}

Note. $r=$ Pearson's correlation coefficient, $\mathrm{BF}=$ Bayes Factor, $95 \% \mathrm{CI}=95 \%$ confidence interval.

Following the guidelines for interpretation of Bayes Factor from Kass and Raftery

9 (1995), our results show moderate evidence of the null hypothesis that no correlation exist

10 between our contextual sensitivity variable and the sample sizes, $p$-values, effect sizes, and

11 standard errors of the included studies, because all of such values of the Bayes Factor fall below

12 1. Importantly, the use of this dual-framework approach allows us to establish that the hypothesized correlations are in favor of the null, something that would not have been possible in a purely frequentist framework, without utilizing additional analytic techniques in the form equivalence testing (Lakens et al., 2018).

In sum, contrary to what we hypothesized in our pre-registration, the results of our contextual sensitivity analysis indicate no statistically significant relationship between how contextually sensitive the included studies were rated and the magnitude of the extracted effect sizes, standard errors, sample sizes, and $p$-values. Hence, our analysis of contextual sensitivity 
1 conveys two main messages: (1) that findings on the relationship between resource scarcity

2 and unethical economic behavior can be considered fairly generalizable across contexts, and

3 (2) that the influence of contextual sensitivity in general might not be as predictive of study

4 outcomes and future replication success, supporting Inbar (2016) concerns for this metric in

5 response to Van Bavel et al. (2016).

Intended as a further exploration and robustness check of our measure of contextual

7 sensitivity, we evaluated how ratings of contextual sensitivity were distributed across research

8 designs, experimental sites, and countries in which the studies were carried out. Our analysis

9 showed no significant difference in contextual sensitivity between research designs $(F(3,40)$

$\left.10=0.16, p=0.920 ; \eta_{p}^{2}=0.01,90 \% \mathrm{CI}[0.00,0.03]\right)$, experimental sites $(F(1,42)=0.03, p=$

$110.871 ; \eta_{p}^{2}=6.36 \mathrm{e}-04,90 \%$ CI $\left.[0.00,0.05]\right)$ or countries $\left(F(11,32)=0.76, p=0.674 ; \eta_{p}^{2}=0.21\right.$,

$1290 \%$ CI $[0.00,0.21])$. Accordingly, contextual sensitivity is not significantly associated with any of these outcomes in the included studies.

15 Discussion

16 Material resource scarcity is a key challenge experienced by individuals around the globe and

17 the implication of these experiences for unethical behavior remains a key issue of debate in moral psychology. Different approaches have been applied to theorize the relationship between material resource scarcity and moral economic behavior and various research designs have been utilized to investigate this relationship empirically. Importantly, general conclusions have been lacking due to mixed and, at times, contradictory findings. This pre-registered systematic review and meta-analysis sought to synthesize existing studies and establish the current known aggregate effect of whether resource scarcity influences individuals' propensity to engage in unethical economic behavior. Overall, our results show that acute experiences of financial 
1 scarcity and physiological scarcity can shift people's propensity to engage in unethical

2 economic behavior. We also show that scarcity reminders exert the same impact. Importantly,

3 our results show that more chronic experiences of scarcity, in the form of lower social class,

4 do not have this effect. Thus, when studying the relationship between scarcity and direct

5 cheating for monetary gains, our findings indicate that it may not be sufficient to rely on "the

6 scarcity mindset" account. Rather, the present results imply that scholars may gain a deeper

7 and more nuanced understanding into this relationship by distinguishing between different

8 types of acute and chronic experiences of material scarcity.

A crucial distinction to make based on the present research is that social class is not a

10 predictor of unethical economic behavior: individuals from lower social classes are not more

11 inclined to engage in unethical economic behavior compared to their wealthier counterparts.

12 Instead, our results suggest that more acute experiences of relative material scarcity can

13 increase individuals' tendency to engage in unethical economic behavior to counteract and

14 alleviate the experienced lack of resources.

15 These results have important implications and suggest that economic decision-making in a context of experienced acute resource scarcity, whether a lack of food, water, or monetary

17 resources, can increase individuals' inclination to engage in unethical economic behaviors. As such, the current findings align with previous studies on scarcity and decision-making, which have argued that different types of material resource scarcity affect behavior in similar ways by making individuals more risk-seeking, impulsive, and focused on regaining resources

21 (Griskevicius et al., 2013; Hamilton et al., 2019; Payne et al., 2017; Shah et al., 2012).

Notably, the observed difference between acute and more chronic forms of scarcity 23 regarding unethical economic behavior might be explained by findings on how scarcity affects 24 behavior at a more general level. Specifically, this difference might be explained by research which has shown that scarcity does not necessarily affect decision-making until individuals 
1 have been reminded of their relative lack of resources (Shah et al., 2012), especially in

2 comparison to others (Goldsmith et al., 2018; Roux et al., 2015). Our findings support this

3 notion; individuals who experience a lack of financial or physiological resources are more

4 inclined to engage in unethical behavior to alleviate this state, and reminders of scarcity

5 activates the same behavioral pattern.

6 Concerning social class, the results of the meta-analysis converge with previous

7 paradigms showing that individuals with a lower (vs. higher) social class, if anything, might

8 exhibit less immoral behavior (Clerke et al., 2018; Piff et al., 2012). While our results do not

9 indicate that individuals constricted by lower social class act more moral than others, our

10 findings clearly reject the idea that lower social class increases the propensity to engage in

11 unethical economic behavior.

As a large portion of the included studies were conducted in very specific contexts, we

13 initially suspected that the generalizability of these findings should vary considerably,

14 consistent with previous research (Van Bavel et al., 2016). However, our results suggest that

15 the difference in contextual sensitivity of the included findings is not associated with the

16 strength of the point estimate or statistical significance of our studied relationships. In

17 particular, we found no significant correlations between the reported sample sizes, effect sizes,

18 standard errors, and $p$-values, on the one hand, and our measure of contextual sensitivity, on

19 the other hand. By the use of Bayes Factor, our analysis instead provided substantial support

20 of the null hypothesis that contextual sensitivity is not significantly correlated with the findings

21 of the included studies. These results indicate that the findings on the relationship between

22 resource scarcity and unethical economic behavior might be relatively generalizable across

23 contexts, to a greater degree than initially expected. Moreover, our sensitivity analysis did not

24 reveal any clear signs of publication bias, with no evidence of data mining either. 
Our meta-analysis showed substantial heterogeneity both in the overall model and across subgroups, except for reminders of scarcity. Such heterogeneity was also documented in a recent meta-analysis on general dishonesty paradigms (Gerlach et al., 2019) and indicates that the decision of whether to engage in unethical economic behavior depends on other relevant factors beyond scarcity.

7 of resource scarcity on unethical economic behavior according to updated conventional standards (Funder \& Ozer, 2019). It is important to emphasize that while such an effect might

9 be small at the level of single events, the accumulated effect of this relationship can have

10 detrimental consequences when aggregated over time and across populations (Funder \& Ozer,

11 2019). Nevertheless, together with the substantial heterogeneity in our models, this also points towards a more complicated interpretation of what motivates individuals to engage in unethical economic behavior. Specifically, the size of our documented effects and the degree of

14 heterogeneity in our models indicate that individual differences (traits) and situational factors (states) are crucial to consider when evaluating whether and when material resource scarcity increases unethical economic behavior (cf. Gerlach et al., 2019). been rising around the world for decades (Piketty, 2020) and has destructive consequences for general well-being, incarceration rates, political polarization, and mortality (Wilkinson \& Pickett, 2011; Wilkinson \& Pickett, 2006). Policy debates often highlight economic inequality, specifically in the Western world, in order to generate increased awareness of the problem. Furthermore, the rise of social media and digital technology increases the dissemination of the immediate affluence of certain segments of the population. Our results suggest that such policy 
1 resource scarcity salient, thereby acting as scarcity reminders with negative downstream effects on people's propensity to engage in unethical economic behaviors across social classes.

\section{$4 \quad$ Limitations}

5 Certain limitations of our analysis should be noted. First, the pooled estimate from our metaanalysis needs to be interpreted against the assumption of potential biases. While our metaanalysis was found to be robust to the impact of publication bias, at least based on conventional tests to detect this bias source, the possibility of publication bias cannot be excluded. Our analysis indicated that significant (vs. non-significant) studies would need to be close to 7 times more likely to be published, which is not unlikely to be true considering previous research on publication bias (Sterling, 1959; Sterling et al., 1995). Nevertheless, considering the number of studies that reported non-significant results and were still published, we consider it unlikely that publication bias should have a material impact on our results.

Second, as is often the case in the social sciences (Muthukrishna et al., 2020; Pollet \& Saxton, 2019; Rad et al., 2018), the majority of our included studies originated from student samples and online panels. Whether such samples enable generalizability claims is still highly debated (Falk et al., 2013; Fosgaard, 2020; Henrich et al., 2010; Muthukrishna et al., 2020), but it is beyond the scope of this article to engage in such meta-scientific discussions.

Third, our meta-analysis resulted in substantial levels of heterogeneity in both our global model and as wells as our second-level analysis. These levels of heterogeneity is 21 comparable to what has been observed in a recent meta-analysis of studies on unethical behavior (Gerlach et al., 2019). However, this heterogeneity is indicative of larger differences in effect sizes between studies, which in turn could indicate differences in precision of the true 24 estimate between studies. While we employed advanced analyses to adjust for this level of 
1 heterogeneity, it remained relatively high. Hence, our pooled estimate should be interpreted

2 with appropriate caution.

Fourth, our measure of contextual sensitivity did not achieve the same level of

4 reliability as in the original work presented by Van Bavel et al. (2016). While we argue that

5 this discrepancy largely stems from the fact that we used expert raters from three distinct

6 disciplines, which should be a more robust measure of contextual sensitivity, future research

7 could aim to assess this construct with different methods, such as crowd-sourced academic

8 rating schemes (Tierney et al., 2021).

Finally, it should be noted that this article has focused specifically on unethical

10 economic behavior. When discussing the larger topic of the relationship between scarcity and

11 morality, it is important to be aware of the sensitivity of the issue and the multiple dimensions

12 of ethical behavior. Hence, while it may be unethical economic behavior if hungry individuals

13 steal money to feed their starving children, a different philosophical perspective could

14 emphasize that such behavior could also reflect a humanitarian and parental action made to

15 protect innocent children. Thus, while a given behavior might be considered immoral from one perspective, it may be perceived as defensible and even altruistic from other perspectives.

\section{Directions for Future Research}

19 The present work is the first of its kind to provide a generalizable quantification of the

20 relationship between material resource scarcity and unethical economic behavior. Furthermore,

21 our results suggest that more chronic forms of scarcity (i.e., lower social class) do not make individuals more inclined to engage in such financially fraudulent actions. However, it remains unknown whether individuals with lower (vs. higher) social class may experience acute

24 influences of relative material scarcity differently with respect to moral judgment and decisionmaking. Given that such an investigation could have important implications for structuring 
1 policy initiatives aimed at helping individuals experiencing chronic resource scarcity, future

2 empirical work should examine this possibility.

We acknowledge that the meta-analysis is based on a relatively small sample $(k=44)$,

4 highlighting the rather narrow set of existing studies in this domain. Although the results of the

5 sensitivity analysis indicate that the findings from the meta-analysis are robust by conventional

6 standards, future research should aim to further test how different forms of material scarcity,

7 both acute and chronic, affect moral economic behavior across populations, contexts, and study

8 paradigms.

While our pre-registered work focused on the impact of material scarcity on

10 individuals' inclination to engage in unethical economic behavior, our review protocol also

11 resulted in a series of articles investigating how this form of scarcity may affect both unethical

12 and prosocial behaviors or prosocial behaviors alone. As a supplement, we included the articles

13 that focused on prosocial behavior but not unethical behavior in a separate meta-analysis

14 reported in Appendix B. It is likely that we did not identify all studies on the relationship

15 between material scarcity and prosocial economic behavior, given that our review protocol was

16 not designed to do so. Nevertheless, the findings from this supplementary analysis showed a

17 small positive and significant effect between material resource scarcity and prosocial economic

18 behaviors. Again, this adds to the inconsistencies in the literature on how resource scarcity

19 affects moral behaviors, and future research is needed to investigate these relationships further.

\section{Conclusion}

22 The results of this systematic review and meta-analysis show that acute experiences of relative

23 resource scarcity in the form of financial scarcity, physiological scarcity, and scarcity

24 reminders increase individuals' inclination to engage in unethical economic behavior. In contrast, more chronic experiences of scarcity in the form of lower socioeconomic status do 
1 not increase the propensity to engage in such behavior. Thus, our investigation highlights that

2 individuals from lower social classes are not more immoral economic decision-makers than

3 their wealthier counterparts. Instead, our findings suggest that acute experiences of relative

4 resource scarcity make individuals more inclined to engage in unethical economic behavior, 5 regardless of their social class. Thus, this meta-analysis emphasizes the benefits of 6 complementing "the scarcity mindset" by distinguishing between different types of acute and 7 chronic experiences of material scarcity to enrich our understanding of scarcity effects in the 8 moral psychology domain.

\section{Data Availability}

11 The data that support the findings of this study are openly available on the Open Science 12 Framework: http://bit.ly/3t1zd8z

\section{Code Availability}

15 All programming codes used to perform the analysis in this study, are available openly 16 available on the Open Science Framework: http://bit.ly/3t1zd8z

\section{Acknowledgements}

19 The study was funded by the Interacting Minds Centre (IMC) at Aarhus University, to which

20 the authors owe their debt of gratitude. The funders had no role in the study design, data

21 collection and analysis, or the decision to prepare, submit, and publish the manuscript.

The authors would like to thank research assistants Frederik Munk Haagerup and

23 Sebastian Scott Engen for their invaluable effort in coding the dataset used in the meta-analysis. 
The authors would also like to thank the contextual coders, Caroline Kjær Børsting,

2 Simon Tobias Karg, and Jacob Dalgaard Christensen for their invaluable help with evaluating 3 the included articles in terms of contextual sensitivity.

\section{Author Contributions}

6 C.T.E., P.M., L.A. and T.O. designed the study; C.T.E. collected the data; C.T.E. analyzed the 7 data; C.T.E., P.M., L.A. and T.O. wrote the final paper.

\section{Competing Interests}

10 The authors declare no competing interest. 


\section{References}

Aksoy, B., \& Palma, M. A. (2019). The effects of scarcity on cheating and in-group favoritism. Journal of Economic Behavior \& Organization, 165, 100-117.

Alvaredo, F., Chancel, L., Piketty, T., Saez, E., \& Zucman, G. (2018). World Inequality Report 2018. Retrieved January 5, 2021, from https://wir2018.wid.world/files/download/wir2018-full-report-english.pdf

Andreoni, J., Nikiforakis, N., \& Stoop, J. (2017). Are the rich more selfish than the poor, or do they just have more money? A natural field experiment [Working Paper]. https://www.nber.org/system/files/working_papers/w23229/w23229.pdf

Aoki, K., Akai, K., \& Onoshiro, K. (2010). Deception and confession: Experimental evidence from a deception game in Japan [Working Paper]. https://www.iser.osakau.ac.jp/library/dp/2010/DP0786.pdf

Atkinson, D. R., Furlong, M. J., \& Wampold, B. E. (1982). Statistical significance, reviewer evaluations, and the scientific process: Is there a (statistically) significant relationship? Journal of Counseling Psychology, 29(2), 189.

Ayal, S., Gino, F., Barkan, R., \& Ariely, D. (2015). Three principles to REVISE people's unethical behavior. Perspectives on Psychological Science, 10(6), 738-741.

Babakus, E., Bettina Cornwell, T., Mitchell, V., \& Schlegelmilch, B. (2004). Reactions to unethical consumer behavior across six countries. Journal of Consumer Marketing, 21(4), 254-263.

Balakrishnan, A., Palma, P. A., Patenaude, J., \& Campbell, L. (2017). A 4-study replication of the moderating effects of greed on socioeconomic status and unethical behaviour. Scientific Data, 4(1), 160120.

Bartko, J. J. (1966). The intraclass correlation coefficient as a measure of reliability. Psychological Reports, 19(1), 3-11. 
1 Bartos, V. (2016). Seasonal scarcity and sharing norms [Working Paper]. CERGE-EI Working Paper Series, 557. https://www.cerge-ei.cz/pdf/wp/Wp557.pdf

3 Birkelund, J., \& Cherry, T. L. (2020). Institutional inequality and individual preferences for honesty and generosity. Journal of Economic Behavior \& Organization, 170, 355-361.

5 Boonmanunt, S., Kajackaite, A., \& Meier, S. (2020). Does poverty negate the impact of social norms on cheating? Games and Economic Behavior, 124, 569-578.

Borenstein, M., Hedges, L. V., Higgins, J. P., \& Rothstein, H. R. (2011). Introduction to metaanalysis. John Wiley \& Sons.

Briers, B., Pandelaere, M., Dewitte, S., \& Warlop, L. (2006). Hungry for money: The desire for caloric resources increases the desire for financial resources and vice versa. Psychological Science, 17(11), 939-943.

Clerke, A. S., Brown, M., Forchuk, C., \& Campbell, L. (2018). Association between Social Class, Greed, and Unethical Behaviour: A Replication Study. Collabra: Psychology,

Curry, O. S., Chesters, M. J., \& Van Lissa, C. J. (2019). Mapping morality with a compass: Testing the theory of 'morality-as-cooperation'with a new questionnaire. Journal of Research in Personality, 78, 106-124.

Debray, T. P. A., Moons, K. G. M., \& Riley, R. D. (2018). Detecting small-study effects and funnel plot asymmetry in meta-analysis of survival data: A comparison of new and existing tests. Research Synthesis Methods, 9(1), 41-50.

DerSimonian, R., \& Laird, N. (1986). Meta-analysis in clinical trials. Controlled Clinical Trials, 7(3), 177-188.

DeWall, C. N., Baumeister, R. F., Gailliot, M. T., \& Maner, J. K. (2008). Depletion makes the heart grow less helpful: Helping as a function of self-regulatory energy and genetic relatedness. Personality and Social Psychology Bulletin, 34(12), 1653-1662.

Dhurandhar, E. J. (2016). The food-insecurity obesity paradox: a resource scarcity hypothesis. 
1 Dubois, D., Rucker, D. D., \& Galinsky, A. D. (2015). Social class, power, and selfishness: When and why upper and lower class individuals behave unethically. Journal of Personality and Social Psychology, 108(3), 436.

Duval, S., \& Tweedie, R. (2000). Trim and fill: a simple funnel-plot-based method of testing and adjusting for publication bias in meta-analysis. Biometrics, 56(2), 455-463.

Egger, M., Smith, G. D., Schneider, M., \& Minder, C. (1997). Bias in meta-analysis detected by a simple, graphical test. $B M J, 315(7109), 629-634$.

Engelmann, J. B., \& Fehr, E. (2016). The slippery slope of dishonesty. Nature Neuroscience, 19(12), 1543-1544.

Falk, A., \& Heckman, J. J. (2009). Lab experiments are a major source of knowledge in the social sciences. Science, 326(5952), 535-538.

Falk, A., Meier, S., \& Zehnder, C. (2013). Do lab experiments misrepresent social preferences? The case of self-selected student samples. Journal of the European Economic Association, 11(4), 839-852.

Fischbacher, U., \& Föllmi-Heusi, F. (2013). Lies in disguise - An experimental study on cheating. Journal of the European Economic Association, 11(3), 525-547.

Fleiss, J. L., \& Cohen, J. (1973). The equivalence of weighted kappa and the intraclass correlation coefficient as measures of reliability. Educational and Psychological Measurement, 33(3), 613-619.

Fosgaard, T. R. (2020). Students cheat more: Comparing the dishonesty of a student sample and a representative sample in the laboratory. The Scandinavian Journal of Economics, 122(1), 257-279.

Funder, D. C., \& Ozer, D. J. (2019). Evaluating effect size in psychological research: Sense and nonsense. Advances in Methods and Practices in Psychological Science, 2(2), 156168.

Gatiso, T. T., Vollan, B., \& Nuppenau, E.-A. (2015). Resource scarcity and democratic elections in commons dilemmas: An experiment on forest use in Ethiopia. Ecological Economics, 114, 199-207. 
1 Gee, J., \& Button, M. (2019). The Financial Cost of Fraud 2019: The Latest Data from Around the World. The Financial Cost of Fraud. Retrieved December 10, 2020, from http://www.crowe.ie/wp-content/uploads/2019/08/The-Financial-Cost-of-Fraud2019.pdf

Gerlach, P., Teodorescu, K., \& Hertwig, R. (2019). The truth about lies: A meta-analysis on dishonest behavior. Psychological Bulletin, 145(1), 1-44.

Gino, F., Ayal, S., \& Ariely, D. (2009). Contagion and differentiation in unethical behavior: The effect of one bad apple on the barrel. Psychological Science, 20(3), 393-398.

Gino, F., \& Galinsky, A. D. (2012). Vicarious dishonesty: When psychological closeness creates distance from one's moral compass. Organizational Behavior and Human Decision Processes, 119(1), 15-26.

Gino, F., \& Pierce, L. (2009a). The abundance effect: Unethical behavior in the presence of wealth. Organizational Behavior and Human Decision Processes, 109(2), 142-155.

Gino, F., \& Pierce, L. (2009b). Dishonesty in the name of equity. Psychological Science, 20(9), 1153-1160.

Gino, F., \& Pierce, L. (2010). Lying to level the playing field: Why people may dishonestly help or hurt others to create equity. Journal of Business Ethics, 95(1), 89-103.

Gino, F., Schweitzer, M. E., Mead, N. L., \& Ariely, D. (2011). Unable to resist temptation: How self-control depletion promotes unethical behavior. Organizational Behavior and Human Decision Processes, 115(2), 191-203.

Gneezy, U., \& Imas, A. (2017). Chapter 10 - Lab in the Field: Measuring Preferences in the Wild. In A. V. Banerjee \& E. Duflo (Eds.), Handbook of Economic Field Experiments (Vol. 1, pp. 439-464). North-Holland.

Goldsmith, K., Roux, C., \& Ma, J. (2018). When seeking the best brings out the worst in consumers: Understanding the relationship between a maximizing mindset and immoral behavior. Journal of Consumer Psychology, 28(2), 293-309.

Graham, J., Haidt, J., Koleva, S., Motyl, M., Iyer, R., Wojcik, S. P., \& Ditto, P. H. (2013). Chapter Two - Moral Foundations Theory: The Pragmatic Validity of Moral Pluralism. 
In P. Devine \& A. Plant (Eds.), Advances in Experimental Social Psychology (Vol. 47, pp. 55-130). Academic Press.

Greene, J. D., \& Paxton, J. M. (2009). Patterns of neural activity associated with honest and dishonest moral decisions. Proceedings of the National Academy of Sciences, 106(30), 12506-12511.

Griskevicius, V., Ackerman, J. M., Cantú, S. M., Delton, A. W., Robertson, T. E., Simpson, J. A., Thompson, M. E., \& Tybur, J. M. (2013). When the economy falters, do people spend or save? Responses to resource scarcity depend on childhood environments. Psychological Science, 24(2), 197-205.

Griskevicius, V., Delton, A. W., Robertson, T. E., \& Tybur, J. M. (2011). Environmental contingency in life history strategies: the influence of mortality and socioeconomic status on reproductive timing. Journal of Personality and Social Psychology, 100(2), 241-254.

Griskevicius, V., Tybur, J. M., Delton, A. W., \& Robertson, T. E. (2011). The influence of mortality and socioeconomic status on risk and delayed rewards: A life history theory approach. Journal of Personality and Social Psychology, 100(6), 1015-1026.

Grissom, R. J., \& Kim, J. J. (2005). Effect sizes for research: A broad practical approach. Lawrence Erlbaum Associates Publishers.

Grundmann, S., \& Lambsdorff, J. G. (2017). How income and tax rates provoke cheating-An experimental investigation of tax morale. Journal of Economic Psychology, 63, 27-42.

Hall, C. C., Zhao, J., \& Shafir, E. (2014). Self-affirmation among the poor: Cognitive and behavioral implications. Psychological Science, 25(2), 619-625.

Hamilton, R., Thompson, D., Bone, S., Chaplin, L. N., Griskevicius, V., Goldsmith, K., Hill, R., John, D. R., Mittal, C., O’Guinn, T., Piff, P., Roux, C., Shah, A., \& Zhu, M. (2019). The effects of scarcity on consumer decision journeys. Journal of the Academy of Marketing Science, 47(3), 532-550.

Harrer, M., Cuijpers, P., \& Ebert, D. (2019). Doing Meta-Analysis in R (Version 1.0.0). Zenodo. https://doi.org/http://doi.org/10.5281/zenodo.2551803 
1 Hartung, J. (1999). An alternative method for meta-analysis. Biometrical Journal: Journal of Mathematical Methods in Biosciences, 41(8), 901-916.

3 Hartung, J., \& Knapp, G. (2001a). On tests of the overall treatment effect in meta-analysis with normally distributed responses. Statistics in Medicine, 20(12), 1771-1782.

Hartung, J., \& Knapp, G. (2001b). A refined method for the meta-analysis of controlled clinical trials with binary outcome. Statistics in Medicine, 20(24), 3875-3889.

Häusser, J. A., Stahlecker, C., Mojzisch, A., Leder, J., Van Lange, P. A., \& Faber, N. S. (2019). Acute hunger does not always undermine prosociality. Nature Communications, 10(1), 1-10.

Hedges, L. V. (1981). Distribution theory for Glass's estimator of effect size and related estimators. Journal of Educational Statistics, 6(2), 107-128.

Hedges, L. V., \& Olkin, I. (2014). Statistical methods for meta-analysis. Academic press.

Henrich, J., Heine, S. J., \& Norenzayan, A. (2010). Most people are not WEIRD. Nature, 466(7302), 29-29.

Herzenstein, M., \& Posavac, S. S. (2019). When charity begins at home: How personal financial scarcity drives preference for donating locally at the expense of global concerns. Journal of Economic Psychology, 73, 123-135.

Higgins, J. P., \& Thompson, S. G. (2002). Quantifying heterogeneity in a meta-analysis. Statistics in Medicine, 21(11), 1539-1558.

Hilbig, B. E., \& Zettler, I. (2015). When the cat's away, some mice will play: A basic trait account of dishonest behavior. Journal of Research in Personality, 57, 72-88.

Huppert, E., Shaw, A., \& Decety, J. (2020). The effect of hunger on children's sharing behavior and fairness preferences. Journal of Experimental Child Psychology, 192, 104786.

Inbar, Y. (2016). Association between contextual dependence and replicability in psychology may be spurious. Proceedings of the National Academy of Sciences, 113(34), E4933E4934. 
IntHout, J., Ioannidis, J. P., \& Borm, G. F. (2014). The Hartung-Knapp-Sidik-Jonkman method for random effects meta-analysis is straightforward and considerably outperforms the standard DerSimonian-Laird method. BMC Medical Research Methodology, 14(1), 112.

Jackson, D., Law, M., Rücker, G., \& Schwarzer, G. (2017). The Hartung-Knapp modification for random-effects meta-analysis: A useful refinement but are there any residual concerns? Statistics in Medicine, 36(25), 3923-3934.

John, L. K., Loewenstein, G., \& Rick, S. I. (2014). Cheating more for less: Upward social comparisons motivate the poorly compensated to cheat. Organizational Behavior and Human Decision Processes, 123(2), 101-109.

Kajackaite, A., \& Gneezy, U. (2017). Incentives and cheating. Games and Economic Behavior, $102,433-444$.

Kass, R. E., \& Raftery, A. E. (1995). Bayes Factors. Journal of the American Statistical Association, 90(430), 773-795.

Kocher, M. G., Schudy, S., \& Spantig, L. (2018). I lie? We lie! Why? Experimental evidence on a dishonesty shift in groups. Management Science, 64(9), 3995-4008.

Koenig, A. L., Cicchetti, D., \& Rogosch, F. A. (2004). Moral development: The association between maltreatment and young children's prosocial behaviors and moral transgressions. Social Development, 13(1), 87-106.

Lakens, D., Scheel, A. M., \& Isager, P. M. (2018). Equivalence Testing for Psychological Research: A Tutorial. Advances in Methods and Practices in Psychological Science, $1(2), 259-269$.

Lee, A. J., \& Zietsch, B. P. (2011). Experimental evidence that women's mate preferences are directly influenced by cues of pathogen prevalence and resource scarcity. Biology Letters, 7(6), 892-895.

Levitt, S. D., \& List, J. A. (2007). What do laboratory experiments measuring social preferences reveal about the real world? Journal of Economic Perspectives, 21(2), 153174. 
1 Liu, Z., Sun, X., \& Tsydypov, L. (2019). Scarcity or luxury: Which leads to adolescent greed? Evidence from a large-scale Chinese adolescent sample. Journal of Adolescence, 77, $32-40$.

Loewenstein, G. (1996). Out of Control: Visceral Influences on Behavior. Organizational Behavior and Human Decision Processes, 65(3), 272-292.

Lüdecke, D. (2018). Effect Size Computation for Meta Analysis. CRAN. https://CRAN.Rproject.org/package $=$ esc

Makambi, K. H. (2004). The effect of the heterogeneity variance estimator on some tests of treatment efficacy. Journal of Biopharmaceutical Statistics, 14(2), 439-449.

Makowski, D., Ben-Shachar, M. S., Patil, I., \& Lüdecke, D. (2020). Methods and algorithms for correlation analysis in R. Journal of Open Source Software, 5(51), 2306.

Mani, A., Mullainathan, S., Shafir, E., \& Zhang, J. (2020). Scarcity and cognitive function around payday: a conceptual and empirical analysis. Journal of the Association for Consumer Research, 5(4).

Mani, A., Mullainathan, S., Shafir, E., \& Zhao, J. (2013). Poverty impedes cognitive function. Science, 341(6149), 976-980.

Mathur, M. B., \& VanderWeele, T. J. (2020). Sensitivity analysis for publication bias in metaanalyses. Journal of the Royal Statistical Society: Series C (Applied Statistics), 69(5), 1091-1119.

Mazar, N., Amir, O., \& Ariely, D. (2008). The dishonesty of honest people: A theory of selfconcept maintenance. Journal of Marketing Research, 45(6), 633-644.

Mazar, N., \& Ariely, D. (2006). Dishonesty in everyday life and its policy implications. Journal of Public Policy \& Marketing, 25(1), 117-126.

Mead, N., Baumeister, R., Gino, F., Schweitzer, M., \& Ariely, D. (2009). Too tired to tell the truth: Self-control resource depletion and dishonesty. Journal of Experimental Social Psychology, 45(3), 594-597. 
Mehta, S., Bastero-Caballero, R. F., Sun, Y., Zhu, R., Murphy, D. K., Hardas, B., \& Koch, G. (2018). Performance of intraclass correlation coefficient (ICC) as a reliability index under various distributions in scale reliability studies. Statistics in Medicine, 37(18), 2734-2752.

Mitchell, V. W., Balabanis, G., Schlegelmilch, B. B., \& Cornwell, T. B. (2009). Measuring Unethical Consumer Behavior Across Four Countries. Journal of Business Ethics, $88(2), 395-412$.

Mitkidis, P., Ayal, S., Shalvi, S., Heimann, K., Levy, G., Kyselo, M., Wallot, S., Ariely, D., \& Roepstorff, A. (2017). The effects of extreme rituals on moral behavior: The performers-observers gap hypothesis. Journal of Economic Psychology, 59, 1-7.

Mittal, C., Griskevicius, V., Simpson, J. A., Sung, S., \& Young, E. S. (2015). Cognitive adaptations to stressful environments: When childhood adversity enhances adult executive function. Journal of Personality and Social Psychology, 109(4), 604-621.

Moher, D., Liberati, A., Tetzlaff, J., Altman, D. G., \& The, P. G. (2009). Preferred Reporting Items for Systematic Reviews and Meta-Analyses: The PRISMA Statement. PLOS Medicine, 6(7), e1000097.

Moher, D., Shamseer, L., Clarke, M., Ghersi, D., Liberati, A., Petticrew, M., Shekelle, P., \& Stewart, L. A. (2015). Preferred reporting items for systematic review and metaanalysis protocols (PRISMA-P) 2015 statement. Systematic Reviews, 4(1), 1.

Mullainathan, S., \& Shafir, E. (2014). Scarcity: The True Cost of Not Having Enough. Penguin Books.

Muthukrishna, M., Bell, A. V., Henrich, J., Curtin, C. M., Gedranovich, A., McInerney, J., \& Thue, B. (2020). Beyond Western, Educated, Industrial, Rich, and Democratic (WEIRD) Psychology: Measuring and Mapping Scales of Cultural and Psychological Distance. Psychological Science, 31(6), 678-701.

Nelson, L. D., \& Morrison, E. L. (2005). The Symptoms of Resource Scarcity: Judgments of Food and Finances Influence Preferences for Potential Partners. Psychological Science, 16(2), 167-173. 
1 Nie, Z., Yang, X., \& Tu, Q. (2020). Resource scarcity and cooperation: Evidence from a gravity irrigation system in China. World Development, 135, 105035.

3 Nowlin, A., Lehman, B., Lawley, K., Waldrop, R., Stein, M., Marinkovich, M., Young, T., \& Grasso, C. (2018). Replication of 'Higher Social Class Predicts Increased Unethical Behavior' at WWU. [Preprint]. osf.io/sxw48

Olkin, I., Dahabreh, I. J., \& Trikalinos, T. A. (2012). GOSH-a graphical display of study heterogeneity. Research Synthesis Methods, 3(3), 214-223.

Orquin, J. L., \& Kurzban, R. (2016). A meta-analysis of blood glucose effects on human decision making. Psychological Bulletin, 142(5), 546.

Otterbring, T., Sundie, J., Jessica Li, Y., \& Hill, S. (2020). Evolutionary psychological consumer research: Bold, bright, but better with behavior. Journal of Business Research, 120, 473-484.

Page, M. J., McKenzie, J., Bossuyt, P., Boutron, I., Hoffmann, T., Mulrow, C., Shamseer, L., Tetzlaff, J., \& Moher, D. (2020). Updating guidance for reporting systematic reviews: development of the PRISMA 2020 statement [Preprint].

Page, M. J., Moher, D., Bossuyt, P., Boutron, I., Hoffmann, T., Mulrow, C., Shamseer, L., Tetzlaff, J., Akl, E., \& Brennan, S. E. (2020). PRISMA 2020 explanation and elaboration: updated guidance and exemplars for reporting systematic reviews [Preprint]. https://osf.io/preprints/metaarxiv/gwdhk/

Payne, B. K., Brown-Iannuzzi, J. L., \& Hannay, J. W. (2017). Economic inequality increases risk taking. Proceedings of the National Academy of Sciences, 114(18), 4643-4648.

Piech, R. M., Pastorino, M. T., \& Zald, D. H. (2010). All I saw was the cake. Hunger effects on attentional capture by visual food cues. Appetite, 54(3), 579-582.

Pier, E. L., Brauer, M., Filut, A., Kaatz, A., Raclaw, J., Nathan, M. J., Ford, C. E., \& Carnes, applications. Proceedings of the National Academy of Sciences, 115(12), 2952-2957. 
1 Piff, P. K., Stancato, D. M., Côté, S., Mendoza-Denton, R., \& Keltner, D. (2012). Higher social class predicts increased unethical behavior. Proceedings of the National Academy of Sciences, 109(11), 4086-4091.

Piketty, T. (2020). Capital and Ideology. Harvard University Press.

Pollet, T. V., \& Saxton, T. K. (2019). How diverse are the samples used in the journals 'evolution \& human behavior'and 'evolutionary psychology'? Evolutionary Psychological Science, 5(3), 357-368.

Potters, J., \& Stoop, J. (2016). Do cheaters in the lab also cheat in the field? European Economic Review, 87, 26-33.

Prediger, S., Vollan, B., \& Herrmann, B. (2014). Resource scarcity and antisocial behavior. Journal of Public Economics, 119, 1-9.

Rad, M. S., Martingano, A. J., \& Ginges, J. (2018). Toward a psychology of Homo sapiens: Making psychological science more representative of the human population. Proceedings of the National Academy of Sciences, 115(45), 11401-11405.

Reynolds, J. J., \& McCrea, S. M. (2015). Exploitative and deceptive resource acquisition strategies: The role of life history strategy and life history contingencies. Evolutionary Psychology, 13(3).

Roe, B. E., \& Just, D. R. (2009). Internal and external validity in economics research: Tradeoffs between experiments, field experiments, natural experiments, and field data. American Journal of Agricultural Economics, 91(5), 1266-1271.

Rosenthal, R., Cooper, H., \& Hedges, L. (1994). Parametric measures of effect size. The Handbook of Research Synthesis, 621(2), 231-244.

Roux, C., Goldsmith, K., \& Bonezzi, A. (2015). On the Psychology of Scarcity: When Reminders of Resource Scarcity Promote Selfish (and Generous) Behavior. Journal of Consumer Research, 42(4), 615-631.

Schwarzer, G., Carpenter, J. R., \& Rücker, G. (2015). Meta-analysis with $R$ (Vol. 4784). Springer. 
1 Seuntjens, T. G., Zeelenberg, M., van de Ven, N., \& Breugelmans, S. M. (2019). Greedy bastards: Testing the relationship between wanting more and unethical behavior. Personality and Individual Differences, 138, 147-156.

Shadish, W. R., Cook, T. D., \& Campbell, D. T. (2002). Experimental and quasi-experimental designs for generalized causal inference. Boston: Houghton Mifflin.

Shah, A. K., Mullainathan, S., \& Shafir, E. (2012). Some consequences of having too little. Science, 338(6107), 682-685.

Shalvi, S., Gino, F., Barkan, R., \& Ayal, S. (2015). Self-serving justifications: Doing wrong and feeling moral. Current Directions in Psychological Science, 24(2), 125-130.

Sharma, E., Mazar, N., Alter, A. L., \& Ariely, D. (2014). Financial deprivation selectively shifts moral standards and compromises moral decisions. Organizational Behavior and Human Decision Processes, 123(2), 90-100.

Simonsohn, U., Nelson, L. D., \& Simmons, J. P. (2014a). p-curve and effect size: Correcting for publication bias using only significant results. Perspectives on Psychological Science, 9(6), 666-681.

Simonsohn, U., Nelson, L. D., \& Simmons, J. P. (2014b). P-curve: a key to the file-drawer. Journal of Experimental Psychology: General, 143(2), 534.

Simonsohn, U., Simmons, J. P., \& Nelson, L. D. (2015). Better P-curves: Making P-curve analysis more robust to errors, fraud, and ambitious P-hacking, a Reply to Ulrich and Miller (2015). Journal of Experimental Psychology: General, 144(6), 1146-1152.

Simpson, J. A., Griskevicius, V., Kuo, S. I., Sung, S., \& Collins, W. A. (2012). Evolution, stress, and sensitive periods: the influence of unpredictability in early versus late childhood on sex and risky behavior. Developmental Psychology, 48(3), 674.

Skrynka, J., \& Vincent, B. T. (2019). Hunger increases delay discounting of food and non-food rewards. Psychonomic Bulletin \& Review, 26(5), 1729-1737.

Sterling, T. D. (1959). Publication decisions and their possible effects on inferences drawn from tests of significance-or vice versa. Journal of the American Statistical Association, 54(285), 30-34. 
1 Sterling, T. D., Rosenbaum, W. L., \& Weinkam, J. J. (1995). Publication decisions revisited: The effect of the outcome of statistical tests on the decision to publish and vice versa. The American Statistician, 49(1), 108-112.

Tierney, W., Hardy, J., Ebersole, C. R., Viganola, D., Clemente, E. G., Gordon, M., Hoogeveen, S., Haaf, J., Dreber, A., Johannesson, M., Pfeiffer, T., Huang, J. L., Vaughn, L. A., DeMarree, K., Igou, E. R., Chapman, H., Gantman, A., Vanaman, M., Wylie, J., Storbeck, J., Andreychik, M. R., McPhetres, J., \& Uhlmann, E. L. (2021). A creative destruction approach to replication: Implicit work and sex morality across cultures. Journal of Experimental Social Psychology, 93, 104060.

Tomasello, M., \& Vaish, A. (2013). Origins of human cooperation and morality. Annual Review of Psychology, 64, 231-255.

Transparency International. (2019). Corruption Perceptions Index 2019. Corruption Perception Index. Retrieved January 14, 2021, from https://www.transparency.org/en/cpi/2019

Trautmann, S. T., Van De Kuilen, G., \& Zeckhauser, R. J. (2013). Social class and (un) ethical behavior: A framework, with evidence from a large population sample. Perspectives on Psychological Science, 8(5), 487-497.

United States Government Accountability Office. (2019). Tax Gap - Multiple Strategies Are Need to Reduce Noncompliance. https://www.gao.gov/assets/700/698969.pdf

Van Bavel, J. J., Mende-Siedlecki, P., Brady, W. J., \& Reinero, D. A. (2016). Contextual sensitivity in scientific reproducibility. Proceedings of the National Academy of Sciences, 113(23), 6454-6459.

Viechtbauer, W., \& Cheung, M. W. L. (2010). Outlier and influence diagnostics for metaanalysis. Research Synthesis Methods, 1(2), 112-125.

Wang, Y., Wang, G., Chen, Q., \& Li, L. (2017). Depletion, moral identity, and unethical behavior: Why people behave unethically after self-control exertion. Consciousness and Cognition, 56, 188-198. 
1 Wiksten, A., Rücker, G., \& Schwarzer, G. (2016). Hartung-Knapp method is not always conservative compared with fixed-effect meta-analysis. Statistics in Medicine, 35(15), 2503-2515.

Wilkinson, R., \& Pickett, K. (2011). The spirit level: Why greater equality makes societies stronger. Bloomsbury Publishing USA.

Wilkinson, R. G., \& Pickett, K. E. (2006). Income inequality and population health: a review and explanation of the evidence. Social science \& medicine, 62(7), 1768-1784.

Williams, E. F., Pizarro, D., Ariely, D., \& Weinberg, J. D. (2016). The Valjean effect: Visceral states and cheating. Emotion, 16(6), 897-902.

Xygalatas, D., Mitkidis, P., Fischer, R., Reddish, P., Skewes, J., Geertz, A. W., Roepstorff, A., \& Bulbulia, J. (2013). Extreme rituals promote prosociality. Psychological Science, 24(8), 1602-1605.

Yam, K. C., Reynolds, S. J., \& Hirsh, J. B. (2014). The hungry thief: Physiological deprivation and its effects on unethical behavior. Organizational Behavior and Human Decision Processes, 125(2), 123-133.

Zwetsloot, P.-P., Van Der Naald, M., Sena, E. S., Howells, D. W., IntHout, J., De Groot, J. A., Chamuleau, S. A., MacLeod, M. R., \& Wever, K. E. (2017). Standardized mean differences cause funnel plot distortion in publication bias assessments. Elife, 6, e24260. 


\section{Appendix A}

\section{Inclusion Criteria and Integrated Scientific Works}

This section provides more detail on the article selection process. First, we only included articles which concerned material resource scarcity. Some articles from our database search concerned cognitive depletion and cognitive scarcity, but such studies were not included based on our pre-registered research rationale. Second, our database search resulted in several studies that only dealt with material resource scarcity but not unethical behavior or vice versa. Because such studies did not investigate the relationship between these two factors, they were also excluded. Third, we excluded review articles as they did not abide to empirically test the relationship between resource scarcity and unethical behavior. If the criteria specified in our pre-registration were fulfilled, we extracted the effect size(s) from the available test statistics in the articles. In cases where such information was not available, we contacted the authors to retrieve the necessary data used in the chosen effect size calculation(s) (Hedges' $g$ ). Two articles had to be excluded, because the authors did not respond to requests about data sharing (Gino \& Pierce, 2009b; Nie et al., 2020). The following tables list all included articles in chronological order. Table A1 represents all studies and conditions on the relationship between resource scarcity and unethical behavior, while Table $\mathbf{A} 2$ represents all studies and conditions on the relationship between resource scarcity and prosocial behavior. Each row represents an extracted effect size.

\section{Table AI}

Resource Scarcity and Unethical Behavior

\begin{tabular}{llcc}
\hline \multicolumn{1}{c}{ Study: Condition } & $n$ & $g$ & Data \\
\hline Koenig et al., 2004: Cheat, abused and neglected & 54 & -0.1585 & yes \\
Koenig et al., 2004: Cheat, abused and nonmaltreated & 56 & 0.4051 & yes \\
Koenig et al., 2004: Cheat, neglected and nonmaltreated & 54 & 0.6843 & yes \\
Koenig et al., 2004: Steal, abused and neglected & 54 & 0.3631 & yes \\
Koenig et al., 2004: Steal, abused and nonmaltreated & 56 & 0.1771 & yes \\
Koenig et al., 2004: Steal, neglected and nonmaltreated & 54 & -0.2412 & yes \\
Koenig et al., 2004: Rule compatible, abused and neglected & 54 & 0.5507 & yes \\
Koenig et al., 2004: Rule compatible, abused and nonmaltreated & 56 & -0.0746 & yes
\end{tabular}


Koenig et al., 2004: Rule compatible, neglected and nonmaltreated Gino et al., 2009: Wealth abundance and overstating performance Gino et al., 2009: Wealth vs. poor and overstated rounds Gino et al., 2009: Wealth vs. weal. bys. and overstated Gino et al., 2009: Weal. bys. vs. poor and overstated Gino et al., 2009: Weal. bys. vs. poor and overstated, other sample Gino et al., 2009: Weal. bys. vs. poor at least one overstated round Gino et al., 2009: Wealthy vs. poor, at least one overstated round Gino \& Pierce 2010a: Weal. judge, poor judge, and poor solver Gino \& Pierce 2010a: Weal. judge, poor judge, and weal. solver Gino \& Pierce 2010a: Weal. judge + solver vs. poor judge + solver Gino \& Pierce 2010b: (Dis)honest reporting Gino \& Pierce 2010b: (Dis)honest reporting, financial cost Aoki et al., 2010: Students vs. non-students, payoff 1000 Aoki et al., 2010: Students vs. non-students, payoff 100 Piff et al., 2012: Cars cutting off other vehicles Piff et al., 2012: Cars cutting off pedestrians Piff et al., 2012: SES and unethical decision-making Piff et al., 2012: SES and unethical behaviour Piff et al., 2012: SES and unethical decision other sample Piff et al., 2012: SES and attitude towards greed Piff et al., 2012: SES and truth telling

Piff et al., 2012: SES and attitude towards greed, other sample Piff et al., 2012: SES and cheating Piff et al., 2012: Features of greed and attitude towards greed Neville, 2012: State inequality and academically dishonest search Daubman et al., 2013: SES, unethical decision making John et al., 2013: Rep. score, aware earning less, and unaware John et al., 2013: Rep. score, aware earning more, unaware John et al., 2013: Rep. score, aware earn. less, unaware, sample 2 John et al., 2013: Rep. score, aware earn. more, unaware, sample 2 Sharma et al., 2013: Deprivation and dishonesty rate Sharma et al., 2013: Deprivation and evolution of dishonesty rate Sharma et al., 2013: Deprivation and dishonesty rate, sample 2 Sharma et al., 2013: Dishonesty rate, hypothetical vs. real gain Sharma et al., 2013: Unfairly deprived and cheating Sharma et al., 2013: Unfairly vs. fairly deprived and cheating Sharma et al., 2013: Leniency for immoral behaviour Sharma et al., 2013: Lenient sentences, deprived vs. non-deprived Trautmainn et al., 2013: Propensity to betray Yam et al., 2014: Cheating and edible prize Yam et al., 2014: Cheating and drinkable prize Yam et al., 2014: Cheating, edible prize, thoughts of hunger Yam et al., 2014: Cheating, drinkable prize, thoughts of hunger Yam et al., 2014: Cheating and edible prize, sample 2

Yam et al., 2014: Cheating and drinkable prize, sample 2 Yam et al., 2014: Cheating and edible prize, sample 3 Yam et al., 2014: Cheating and non-edible prize Yam et al., 2014: Cheating, drinkable prize and thirst Yam et al., 2014: Cheating, non-drinkable prize and thirst Prediger et al., 2014: Low-yield area, JoD, Table 2, reg. 1 Prediger et al., 2014: Low-yield area, JoD, Table 2, reg. 2 Prediger et al., 2014: Low-yield area, JoD, Table 2, reg. 3 Prediger et al., 2014: Low-yield area, JoD, Table 2, reg. 4 Prediger et al., 2014: Low-yield area, JoD, Table 2, reg. 5 Prediger et al., 2014: Low-yield area, JoD, Table 2, reg. 6 Prediger et al., 2014: Low-yield area, JoD, Table 2, reg. 7 Prediger et al., 2014: Poor pasture quality, JoD, Table 2, reg 8 Gatiso et al., 2015: Scarcity, cooperative behaviour Reynolds et al., 2015: Cheating, FLHC

\begin{tabular}{|c|c|}
\hline-0.6078 & yes \\
\hline 1.359 & yes \\
\hline 1.1059 & yes \\
\hline 0.3172 & yes \\
\hline 0.8265 & yes \\
\hline 1.415 & yes \\
\hline 0.9674 & yes \\
\hline 1.25 & yes \\
\hline-0.6211 & yes \\
\hline 0.7822 & yes \\
\hline 0.4637 & yes \\
\hline & n.r. \\
\hline & n.r. \\
\hline-0.2808 & yes \\
\hline-0.02 & yes \\
\hline-0.2411 & yes \\
\hline-0.3641 & yes \\
\hline-0.4692 & yes \\
\hline-0.5567 & yes \\
\hline-0.4044 & yes \\
\hline-0.7663 & yes \\
\hline 0.4909 & yes \\
\hline-0.3437 & yes \\
\hline-0.2817 & yes \\
\hline 0.5685 & yes \\
\hline 0.992 & yes \\
\hline 0.4892 & yes \\
\hline 0.487 & yes \\
\hline 0.1937 & yes \\
\hline 0.3902 & yes \\
\hline 0.2095 & yes \\
\hline 0.7302 & yes \\
\hline 0.5767 & yes \\
\hline 0.5692 & yes \\
\hline 1.0026 & yes \\
\hline 0.237 & yes \\
\hline 0.295 & yes \\
\hline 0.7774 & yes \\
\hline 0.3091 & yes \\
\hline 0.0839 & yes \\
\hline 0.2345 & yes \\
\hline-0.2335 & yes \\
\hline 0.2532 & yes \\
\hline-0.2532 & yes \\
\hline 0.51 & yes \\
\hline-0.9134 & yes \\
\hline 0.3326 & yes \\
\hline-0.7739 & yes \\
\hline 0.3748 & yes \\
\hline-0.3695 & yes \\
\hline 0.2049 & yes \\
\hline 0.285 & yes \\
\hline 0.1956 & yes \\
\hline 0.1968 & yes \\
\hline-0.0618 & yes \\
\hline 0.1646 & yes \\
\hline 0.1685 & yes \\
\hline 0.2342 & yes \\
\hline-0.8052 & yes \\
\hline 0.3735 & yes \\
\hline
\end{tabular}


Reynolds et al., 2015: Cheating, SLHC

Reynolds et al., 2015: EDRASS factor 1, FLHC

Reynolds et al., 2015: EDRASS factor 1, SLHC

Reynolds et al., 2015: EDRASS factor 3, FLHC

Roux et al., 2015: Recognizing words related to competition

Roux et al., 2015: Higher competitive orientation

Roux et al., 2015: Choosing absolute maximum gain

$-0.1274$

0.0085

$-0.1049$

0.42

0.7416

Roux et al., 2015: Choosing relative maximum gain

0.2769

Roux et al., 2015: Allocating less money to other player, dictator

0.3085

Williams et al., 2016: Lying for water bottle, thirsty vs. not thirsty

0.3355

Williams et al., 2016: Lying for water bottle, sample 2

Williams et al., 2016: Lying for a pen, thirsty vs. not thirsty

Williams et al., 2016: Lying for water bottle, sample 3

Williams et al., 2016: Lying for water bottle, (sample 1+2+3)

Balakrishna et al., 2017: Greed attitude and unethical

Balakrishna et al., 2017: Low SES and behaviour

Balakrishna et al., 2017: Greed attitude, behaviour and sample 2

Balakrishna et al., 2017: Low SES, behaviour and sample 2

Balakrishna et al., 2017: Greed attitude, behaviour., sample 3

Balakrishna et al., 2017: Low SES, behaviour, sample 3

Balakrishna et al., 2017: Greed attitude, behaviour and sample 4

Balakrishna et al., 2017: Low SES, behaviour and sample 4

Andreoni et al., 2017: Return misdelivered envelope

Andreoni et al., 2017: Return rate, cash treatment

Andreoni et al., 2017: Return rate, bank transfer treatment

Goldsmith et al., 2017: Moral disengagement

0.787

0.459

0.58

0.425

0.56

0.4432

0.1108

0.2636

0.0145

0.2879

0.0272

0.4521

0.0219

$-0.4638$

$-0.4752$

$-0.3114$

Goldsmith et al., 2017: Economic cheating

Goldsmith et al., 2017: Economic cheating, threat to self-concept

0.0693

0.2727

0.1429

Goldsmith et al., 2017: Immoral behaviour, housing

Goldsmith et al., 2017: Acceptance of immoral behaviour

Mitkidis et al., 2018: Die roll cheating, poor vs. affluent

Mitkidis et al., 2018: Die roll cheating, poor SES vs. affluent

Mitkidis et al., 2018: Die roll cheat., low affluent and pov.

Mitkidis et al., 2018: Die roll cheat., affluence high and pov. low

Mitkidis et al., 2018: Die roll cheat., pov. low and neutral low

Mitkidis et al., 2018: Die roll cheat., neutral high and pov. low

Mitkidis et al., 2018: Die roll cheat., affluence low and pov. high

Mitkidis et al., 2018: Die roll cheat, high affluent and pov.

Mitkidis et al., 2018: Die roll cheat., neutral low and pov. high

Mitkidis et al., 2018: Die roll cheat., neutral high and pov. high

Nowlin et al., 2018: SES and unethical behaviour

Nowlin et al., 2018: Greed attitude and behaviour

Clerke et al., 2018: SES and lying

Clerke et al., 2018: SES and greed attitude

Clerke et al., 2018: SES and lying, sample 2

Clerke et al., 2018: SES and greed attitude, sample 2

Aksoy et al., 2019: Cheating for themselves

Aksoy et al., 2019: Cheating for in-group

Aksoy et al., 2019: Cheating for out-of-group

Seuntjens et al., 2019: Dispositional greed, behaviour, American

0.4091

0.1756

$-0.3001$

0.0174

0.004

$-0.052$

$-0.0803$

$-0.1483$

0.1793

0.1123

0.1944

$-0.0188$

0.3535

0.0114

$-0.0399$

yes

yes

yes

yes

yes

yes

yes

yes

yes

yes

yes

yes

yes

yes

yes

yes

yes

yes

yes

yes

yes

yes

yes

yes

yes

yes

yes

yes

yes

yes

yes

yes

yes

yes

yes

yes

yes

yes

yes

yes

yes

yes

yes

yes

yes

$-0.14$

0.0399

$-0.3442$

$-0.0455$

$-0.1032$

0.1132

0.6045

Seuntjens et al., 2019: Dispositional greed, behaviour, Belgian

Seuntjens et al., 2019: Dispositional greed, behaviour, Dutch

Seuntjens et al., 2019: Dispositional greed, justifiable to engage

Seuntjens et al., 2019: Dispositional greed, transgressions accept

0.6285

0.4079

0.7943

0.5828

Seuntjens et al., 2019: Greed, accepting a bribe

0.389 
Seuntjens et al., 2019: DGS, bribe

Seuntjens et al., 2019: DGS, wallet

$\begin{array}{ccc}172 & 0.5129 & \text { yes } \\ 302 & 0.6496 & \text { yes } \\ 302 & 0.6068 & \text { yes } \\ 3200 & 0.0734 & \text { yes } \\ 192 & 0.9105 & \text { yes } \\ 192 & 1.4455 & \text { yes } \\ 192 & 1.4674 & \text { yes } \\ 284 & 0.0119 & \text { yes } \\ 274 & 0.1058 & \text { yes }\end{array}$

Seuntjens et al., 2019: DGS, cheat

Liu et al., 2019: Greed, childhood SES

Birkelund et al., 2020: Cheat, no adv. + unequal, no adv. + equal

Birkelund et al., 2020: Cheat, no adv. + unequal, adv. + equal

Birkelund et al., 2020: Cheat, no adv. + unequal, adv. + unequal

274

yes

Note. $n=$ number of participants; $g=$ Hedges' $g$ effect size; data $=$ data available in original article or by request to authors (with yes $=$ data obtained; n.r. $=$ no response from authors)

Table A2

Resource Scarcity and Prosocial Behavior

\begin{tabular}{|c|c|c|c|}
\hline Study: Condition & $n$ & $g$ & Data \\
\hline Koenig et al., 2004: Helping gesture, abused and neglected & 54 & -0.2956 & yes \\
\hline Koenig et al., 2004: Helping gesture, abused and nonmaltreated & 56 & -0.069 & yes \\
\hline Koenig et al., 2004: Helping gesture, neglected and nonmaltreated & 54 & 0.2151 & yes \\
\hline Koenig et al., 2004: Comfort gesture, abused and neglected & 54 & 0.2981 & yes \\
\hline Koenig et al., 2004: Comfort gesture, abused and nonmaltreated & 56 & 0.2304 & yes \\
\hline Koenig et al., 2004: Comfort gesture, neglected and nonmaltreated & 54 & -0.0946 & yes \\
\hline Koenig et al., 2004: Donation, abused and neglected & 54 & -0.3077 & yes \\
\hline Koenig et al., 2004: Donation, abused and nonmaltreated & 56 & -0.4005 & yes \\
\hline Koenig et al., 2004: Donation, neglected and nonmaltreated & 54 & -0.0844 & yes \\
\hline Koenig et al., 2004: Guilt, abused and neglected & 54 & -0.1184 & yes \\
\hline Koenig et al., 2004: Guilt, abused and nonmaltreated & 56 & -0.0748 & yes \\
\hline Koenig et al., 2004: Guilt, neglected and nonmaltreated & 54 & 0.057 & yes \\
\hline Koenig et al., 2004: Empathy, abused and neglected & 54 & -0.0519 & yes \\
\hline Koenig et al., 2004: Empathy, abused and nonmaltreated & 56 & -0.2335 & yes \\
\hline Koenig et al., 2004: Empathy, neglected and nonmaltreated & 54 & -0.1762 & yes \\
\hline Briers et al., 2006: Hunger and willingness to pay to charity & 66 & 0.19 & yes \\
\hline Briers et al., 2006: Food scent and willingness to pay to charity & 58 & 0.5297 & yes \\
\hline DeWall et al., 2008: Self-regulation and helping others & 19 & 0.9869 & yes \\
\hline Dewall et al., 2008: Self-regulation, helping strangers vs. family & 291 & 2.19 & yes \\
\hline DeWall et al., 2008: Self-regulation and helping strangers & 291 & 0.2095 & yes \\
\hline Harel \& Kohut, 2014: Willing to donate, experienced hunger & 108 & 0.3282 & yes \\
\hline Harel \& Kohut, 2014: Willing to donate, hungry vs. satiated & 196 & 0.244 & yes \\
\hline Roux et al., 2015: Wanting to donate & 52 & 0.5614 & yes \\
\hline Roux et al., 2015: Choosing joint maximum gain & 69 & -0.4946 & yes \\
\hline Roux et al., 2015: Likelihood of donating, private donation & 360 & 0.3466 & yes \\
\hline Roux et al., 2015: Likelihood of donating, public donation & 360 & 0.214 & yes \\
\hline Bartos et al., 2018: Generosity, one-shot dictator game & 136 & -0.0702 & yes \\
\hline Bartos et al., 2018: Generosity, third-party punishment game & 136 & -0.0729 & yes \\
\hline Bartos et al., 2018: Fairness, third-party punishment game & 136 & -0.4631 & yes \\
\hline Herzenstein et al., 2019: Willingness to donate (donation rate) & 107 & -0.2102 & yes \\
\hline Herzenstein et al., 2019: Willingness to donate (charity size) & 107 & -0.0241 & yes \\
\hline Herzenstein et al., 2019: Donation size to UNICEF US & 107 & 0.2176 & yes \\
\hline Herzenstein et al., 2019: Donation size to UNICEF Africa & 107 & -0.2803 & yes \\
\hline Herzenstein et al., 2019: Donation, someone else's money & 229 & 0.2996 & yes \\
\hline Herzenstein et al., 2019: Donation size to local charity & 158 & 0.4514 & yes \\
\hline Herzenstein et al., 2019: Donation size to far away charity & 158 & -0.1834 & yes \\
\hline Herzenstein et al., 2019: Donation size to East Coast & 94 & 0.425 & yes \\
\hline Herzenstein et al., 2019: Asian origin, scarcity, donation & 405 & -0.586 & yes \\
\hline Herzenstein et al., 2019: Asian origin, abundance, donation & 405 & 0.0094 & yes \\
\hline Herzenstein et al., 2019: Donation size, experience, scarcity & 803 & 0.2738 & yes \\
\hline Herzenstein et al., 2019: Donation size, experience, abundance & 803 & 0.687 & yes \\
\hline
\end{tabular}


Herzenstein et al., 2019: Donation size, lifesaving, scarcity

$\begin{array}{ccc}803 & 0.2682 & \text { yes } \\ 803 & 0.1191 & \text { yes } \\ 62 & 0.0502 & \text { yes } \\ 62 & 0.47 & \text { yes } \\ 103 & -0.1044 & \text { yes } \\ 103 & -0.2481 & \text { yes } \\ 103 & -0.1937 & \text { yes } \\ 267 & 0.071 & \text { yes } \\ 203 & 0.2975 & \text { yes } \\ 192 & -0.4305 & \text { yes } \\ 192 & -0.7415 & \text { yes } \\ 192 & -1.0321 & \text { yes } \\ 312 & & \text { n.r. }\end{array}$

Herzenstein et al., 2019: Donation size, lifesaving, abundance

Häusser et al., 2019: Contribution to common pool in PGG

Häusser et al., 2019: Stag hunt game

Häusser et al., 2019: Stag hunt game (larger sample size)

Häusser et al., 2019: Social mindfulness

Häusser et al., 2019: Willingness to accept unfair offers in UG

Häusser et al., 2019: Scarcity, SVO scores

Huppert et al., 2019: Generosity, dictator game

Birkelund et al., 2020: Offer, no adv. + unequal, no adv. + equal

Birkelund et al., 2020: Offer, no adv. + unequal, adv. + equal

$\frac{\text { Nie et al., 2020: Water scarcity, farmer's willingness to cooperate }}{\text { Note. } n=\text { number of participants; } g=\text { Hedges' } g \text { effect size; data }=\text { data available in original article or by request }}$

$\frac{\text { Nie et al., 2020: Water scarcity, farmer's willingness to cooperate }}{\text { Note. } n=\text { number of participants; } g=\text { Hedges' } g \text { effect size; data }=\text { data available in original article or by request }}$ to authors (with yes $=$ data obtained; n.r. $=$ no response from authors) 


\section{Appendix B}

\section{Supplementary Review and Meta-Analysis on Prosocial Behavior}

As noted in our methods section (see sub-section, Search), our pre-registered review protocol (https://bit.ly/3t1zd8z) restricted our search terms and inclusion criteria to research that had investigated the relationship between resource scarcity and unethical behavior. However, as previously noted, our database search resulted in a series of articles that either investigated how scarcity might affect both unethical and prosocial behavior or which purely sought to investigate how scarcity might affect prosocial behavior. While considered irrelevant to the main body of the systematic review and meta-analysis, we decided that it would still be relevant to outline the results of such studies in connection with our main focus on unethical behavior. Consequently, the below section outlines the meta-analytical results on how resource scarcity might affect prosocial behavior.

\section{Meta-analysis}

As with the main analysis presented in the paper, the meta-analysis of the relationship between resource scarcity and prosocial behavior followed a hierarchical approach, in which we firstly analyzed a global model on all the included studies, before breaking the analysis down to the subgroup level. Here, it should be noted that this supplementary analysis only included three subgroups: Financial Scarcity, Reminders of Scarcity, and Physiological Scarcity. The results are presented in Table B1. Again, the key variables of interest in this analysis is the Standardized Mean Difference (SMD) in the form of Hedges' $g$, the percentage of variability in effect sizes $I^{2}$, and the between study variance in the form of $\tau^{2}$. 


\section{Table B1}

Supplementary analysis of the relationship between resource scarcity and prosocial behavior

Results prior to heterogeneity adjustment

\begin{tabular}{lccccccc} 
Group & $k$ & $N$ & SMD & $95 \%$ CI & $p$ & $I^{2}$ & $\tau^{2}$ \\
\hline All studies & 21 & 3307 & 0.0823 & {$[-0.0693 ; 0.2338]$} & 0.2708 & $66.4 \%$ & 0.0872 \\
Financial Scarcity & 8 & 1457 & -0.0311 & {$[-0.3531 ; 0.2909]$} & 0.8261 & $78.4 \%$ & 0.1180 \\
Reminders of Scarcity & 3 & 481 & 0.0794 & {$[-1.2674 ; 1.4262]$} & 0.0219 & $80.6 \%$ & 0.4561 \\
Physiological Scarcity & 10 & 1369 & 0.1751 & {$[0.0319 ; 0.3184]$} & 0.8235 & $0.0 \%$ & 0.1872
\end{tabular}

Results post heterogeneity adjustment

\begin{tabular}{lccccccc}
\multicolumn{1}{c}{ Group } & $k$ & $N$ & SMD & $95 \%$ CI & $p$ & $I^{2}$ & $\tau^{2}$ \\
\hline All studies & 17 & 2622 & 0.1672 & {$[0.0646 ; 0.2697]$} & 0.0033 & $21.9 \%$ & 0.0247 \\
Financial Scarcity & 6 & 860 & 0.1274 & {$[-0.1673 ; 0.4222]$} & 0.3169 & $56.2 \%$ & 0.0534 \\
Reminders of Scarcity & 2 & 412 & 0.3550 & {$[-0.1738 ; 0.8838]$} & 0.0743 & $0.0 \%$ & 0.0015 \\
Physiological Scarcity & 9 & 1350 & 0.1622 & {$[0.0552 ; 0.2693]$} & 0.0081 & $0.0 \%$ & 0.0092 \\
\hline
\end{tabular}

Note. $k=$ number of studies, $N=$ sample size, $\mathrm{SMD}=$ Standardized Mean Difference by Hedges' $g, 95 \% \mathrm{CI}=$ $95 \%$ confidence interval, $p=$ p-value, $I^{2}=$ percentage of variability in effect sizes, $\tau^{2}=$ between-study variance.

The analysis of all supplementary studies on the relationship between resource scarcity and prosocial behavior revealed an insignificant pooled effect size of 0.0823 . The results of the global model also revealed substantial heterogeneity $I^{2}=66.4 \%$. Grouping the analysis by the subgroup defined by the main independent variables strongly reduced the degree of heterogeneity for studies on physiological scarcity, $I^{2}=0.0 \%$, while revealing that studies on financial scarcity $\left(I^{2}=78.4 \%\right)$ and reminders of scarcity $\left(I^{2}=80.6 \%\right)$ accounted for a large degree of the observed heterogeneity in the overall model. Consequently, the second-level subgroup analysis revealed insignificant and very small effects sizes for the subgroups with high-levels of heterogeneity. On the contrary, the subgroup on physiological scarcity yielded a statistically significant small effect size of 0.1751 .

A GOSH-analysis of heterogeneity revealed that 4 articles $(k=4)$ accounted for a large degree of the observed heterogeneity (Birkelund \& Cherry, 2020) (DeWall et al., 2008) (Herzenstein \& Posavac, 2019) (Roux et al., 2015). Rerunning the analysis without these 
studies reduced the heterogeneity of the global model to $I^{2}=21.9 \%$ and yielded a revised statistically significant pooled effect size estimate of 0.1672 . Furthermore, this analysis reduced the heterogeneity of the two subgroups financial scarcity and reminders of scarcity to $I^{2}=56.2 \%$ and $I^{2}=0.00 \%$, respectively. The heterogeneity adjusted subgroup analysis yielded a significant effect size estimate of 0.1622 , while still leaving the pooled estimate for the two other subgroups insignificant. A forest plot based on the heterogeneity adjusted subgroup analysis is presented in Figure B1.

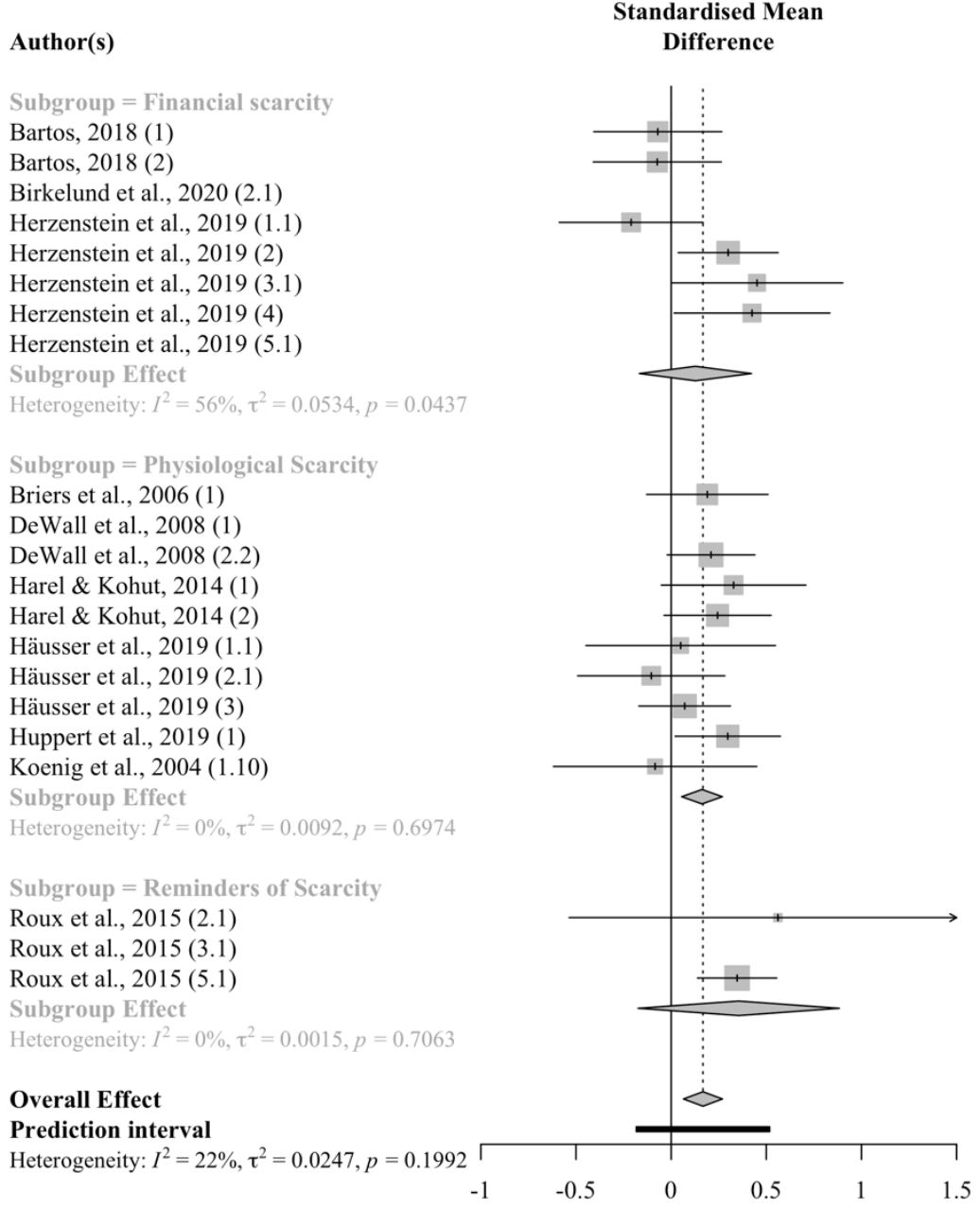

\begin{tabular}{|c|c|c|}
\hline g & $95 \%$ CI & Weigth \\
\hline-0.07 & {$[-0.41 ; 0.27]$} & $6.1 \%$ \\
\hline-0.07 & {$[-0.41 ; 0.26]$} & $6.1 \%$ \\
\hline-0.43 & {$[-0.83 ;-0.03]$} & $0.0 \%$ \\
\hline-0.21 & {$[-0.59 ; 0.17]$} & $5.3 \%$ \\
\hline 0.30 & {$[0.04 ; 0.56]$} & $7.7 \%$ \\
\hline 0.45 & {$[0.00 ; 0.90]$} & $4.3 \%$ \\
\hline 0.42 & {$[0.02 ; 0.83]$} & $4.8 \%$ \\
\hline-0.59 & {$[-0.90 ;-0.28]$} & $0.0 \%$ \\
\hline 0.13 & {$[-0.17 ; 0.42]$} & $34.3 \%$ \\
\hline 0.19 & {$[-0.13 ; 0.51]$} & $6.4 \%$ \\
\hline 0.99 & {$[0.03 ; 1.94]$} & $0.0 \%$ \\
\hline 0.21 & {$[-0.02 ; 0.44]$} & $8.6 \%$ \\
\hline 0.33 & {$[-0.05 ; 0.71]$} & $5.3 \%$ \\
\hline 0.24 & {$[-0.04 ; 0.53]$} & $7.3 \%$ \\
\hline 0.05 & {$[-0.45 ; 0.55]$} & $3.7 \%$ \\
\hline-0.10 & {$[-0.49 ; 0.28]$} & $5.2 \%$ \\
\hline 0.07 & {$[-0.17 ; 0.31]$} & $8.3 \%$ \\
\hline 0.30 & {$[0.02 ; 0.57]$} & $7.4 \%$ \\
\hline-0.08 & {$[-0.62 ; 0.45]$} & $3.3 \%$ \\
\hline 0.16 & {$[0.06 ; 0.27]$} & $55.5 \%$ \\
\hline 0.56 & {$[-0.54 ; 1.66]$} & $1.0 \%$ \\
\hline-0.49 & {$[-0.97 ;-0.01]$} & $0.0 \%$ \\
\hline 0.35 & {$[0.14 ; 0.55]$} & $9.2 \%$ \\
\hline 0.35 & {$[-0.17 ; 0.88]$} & $10.1 \%$ \\
\hline & $\begin{array}{l}{[0.06 ; 0.27]} \\
{[-0.18 ; 0.52]}\end{array}$ & $100.0 \%$ \\
\hline
\end{tabular}

Figure B1. Forest plot, adjusted for heterogeneity, of the effect sizes for each of the three subgroups as well as the overall effect of resource scarcity on prosocial behavior. Error bars 
represent $95 \%$ confidence intervals. Grey diamonds depict the pooled effect for the subgroups. The grey diamond connected to the dotted line depicts the overall effect of the model. The black line depicts the prediction interval of the overall model.

In sum, the second-level model adjusted for heterogeneity supports an analysis of the included data at the subgroup level. Our supplementary analysis shows that resource scarcity in the form of physiological scarcity has a positive significant effect on individuals' propensity to engage in prosocial behaviors, but that such an effect does not exist for the subgroups on financial scarcity or reminders of scarcity. On the global level, our model results in a small-tomedium effect size (.17) on the relationship between material resource scarcity and prosocial behavior, largely driven by the results in the subgroup on physiological scarcity. 


\section{Appendix C}

\section{Supplementary Robustness Analyses}

\section{Sensitivity Analysis of Estimation Algorithm}

Estimating the variance of the pooled effect in a random-effects model meta-analysis using the Hartung-Knapp-Sidik-Jonkman (HKSJ) method has been shown to provide more robust estimates of the variance than the widely used DerSimonian-Laird estimator (IntHout et al., 2014). However, to address recent work on residual concerns when using the (HKSJ) method (Jackson et al., 2017), we followed recommendations from Wiksten et al. (2016) and conducted a sensitivity analysis of the derived variance of the meta-analytic effects by applying the widely used DerSimonian-Laird estimator (DerSimonian \& Laird, 1986).

Our analysis showed no difference in effect size estimates between the two methods. The results of the sensitivity analysis are presented in Figure C1. This analysis hence supports our initial prediction that the main results of our meta-analysis is robust to the use of different estimation algorithms.

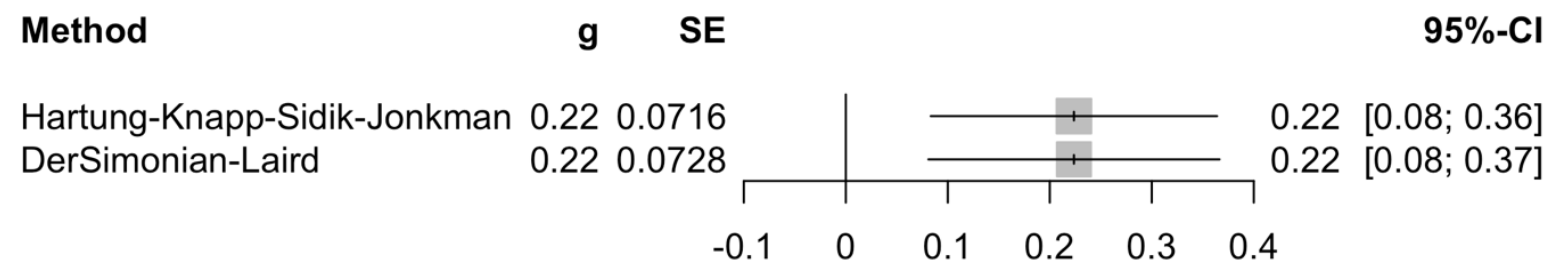

Figure C1. Sensitivity analysis of the difference between the Hartung-Knapp-Sidik-Jonkman estimation algorithm and the DerSimonian-Laird estimation algorithm. The algorithm used in the main meta-analysis is robust due to the extremely small difference in pooled estimates. 


\section{Meta-analysis of all extracted effect sizes}

To further assess the robustness of our main findings on the relationship between resource scarcity and unethical behavior, we carried out a random-effect model meta-analysis by the use of every single extracted effect size from the included articles. While this entailed a redundancy in sample sizes (i.e., multiple tests for the same sample size) and, consequently, high levels of heterogeneity, we argue that such an analysis provides further validity and robustness of our main findings, given that this analysis was conducted on a much larger data set than that of the original. Table $\mathbf{C} 1$ reports the results this analysis.

\section{Table C1}

Supplementary analysis of the relationship between resource scarcity and unethical behavior

Results prior to heterogeneity adjustment

\begin{tabular}{lccccccc}
\multicolumn{1}{c}{ Group } & $k$ & $N$ & SMD & $95 \%$ CI & $p$ & $I^{2}$ & $\tau^{2}$ \\
\hline All studies & 135 & 26,901 & 0.1973 & {$[0.1202 ; 0.2743]$} & $<0.0001$ & $84.7 \%$ & 0.4192 \\
Financial Scarcity & 55 & 7927 & 0.2959 & {$[0.1539 ; 0.4379]$} & $<0.0001$ & $86.2 \%$ & 0.2429 \\
Reminders of Scarcity & 29 & 8555 & 0.2851 & {$[0.1701 ; 0.4000]$} & $<0.0001$ & $79.8 \%$ & 0.0719 \\
Physiological Scarcity & 24 & 1836 & 0.1241 & {$[-0.0778 ; 0.3259]$} & $<0.0001$ & $78.8 \%$ & 0.1784 \\
Social Class & 27 & 8583 & -0.0127 & {$[-0.1501 ; 0.1248]$} & $<0.0001$ & $78.2 \%$ & 0.1006
\end{tabular}

Results post heterogeneity adjustment

\begin{tabular}{lccccccc} 
Group & $k$ & $N$ & SMD & $95 \%$ CI & $p$ & $I^{2}$ & $\tau^{2}$ \\
\hline All studies & 75 & 11,810 & 0.1784 & {$[0.1071 ; 0.2497]$} & $<0.0001$ & $65.7 \%$ & 0.1797 \\
Financial Scarcity & 31 & 3223 & 0.1784 & {$[0.0649 ; 0.2920]$} & 0.0032 & $65.6 \%$ & 0.0737 \\
Reminders of Scarcity & 15 & 5336 & 0.2045 & {$[0.0669 ; 0.3422]$} & 0.0066 & $62.0 \%$ & 0.0422 \\
Physiological Scarcity & 16 & 634 & 0.2374 & {$[0.0291 ; 0.4457]$} & 0.0282 & $64.8 \%$ & 0.1081 \\
Social Class & 13 & 5898 & 0.0925 & {$[-0.0917 ; 0.2768]$} & 0.2952 & $69.6 \%$ & 0.0703 \\
\hline
\end{tabular}

Note. $k=$ number of studies, $N=$ sample size, $\mathrm{SMD}=$ Standardized Mean Difference by Hedges' $g, 95 \% \mathrm{CI}=$ $95 \%$ confidence interval, $p=$ p-value, $I^{2}=$ percentage of variability in effect sizes, $\tau^{2}=$ between-study variance.

The robustness analysis of all included effect sizes revealed a significant overall effect of 0.1973, close to, but lower than that of the main findings. As expected, the global model also 
revealed substantial heterogeneity $I^{2}=84.7 \%$. An identical pattern emerged in the subgroup analysis. Here, all estimates for the subgroups were highly significant and yielded positive effect sizes for all groups except that of social class.

Following previous procedures, we conducted a GOSH analysis (Olkin et al., 2012) to explore the observed heterogeneity in our models. As expected, due to the redundancy in sample sizes, this analysis revealed that 60 effect sizes accounted for the cluster of observed heterogeneity in the model. Excluding such studies in a subsequent analysis reduced the heterogeneity of the global model to $I^{2}=65.7 \%$ (close to that of the main model) and revealed a revised statistically significant pooled effect size estimate of 0.1784 . Moreover, the revision of the model reduced the heterogeneity for all subgroups and hence yielded revised effect estimates. Specifically, the heterogeneity adjusted model lowered the effect size estimates for the subgroups of financial scarcity $(0.1784)$ and reminders of scarcity $(0.2045)$, while increasing the pooled estimate for the subgroup on physiological scarcity (0.2374). All of these three subgroups, however, still yielded statistically significant estimates in the revised model. On the contrary, while the effect size estimate for the subgroup on social class increased to become positive, this estimate was no longer significant in the revised model, which again mimics the relationship found in our main analysis.

In sum, our supplementary analysis adds further robustness to our main findings by showing a largely identical relationship, wherein resource scarcity increases individuals' propensity to engage in unethical behavior. Again, our models support an analysis at the subgroup level by showing that resource scarcity in the form of (1) financial scarcity, (2) reminders of scarcity, and (3) physiological scarcity significantly affects individuals' propensity to engage in unethical behavior, while social class does not. 